\title{
Learned Generosity? A Field Experiment with Parents and their Children
}

\author{
Avner Ben-Ner ${ }^{\mathrm{a}}$, John A. List ${ }^{\mathrm{b}}$, Louis Putterman ${ }^{\mathrm{c}}$ and Anya Samek ${ }^{\mathrm{d}}$ \\ ${ }^{\mathrm{a}}$ University of Minnesota \\ ${ }^{\mathrm{b}}$ University of Chicago \& NBER \\ ${ }^{\mathrm{c}}$ Brown University \\ ${ }^{d}$ University of Southern California
}

December 2015

\begin{abstract}
An active area of research within the social sciences concerns the underlying motivation for sharing scarce resources and engaging in other pro-social actions. We develop a theoretical framework that sheds light on the developmental origins of social preferences by providing mechanisms through which parents transmit preferences for generosity to their children. Then, we conduct a field experiment with nearly 150 3-5 year old children and their parents, measuring (1) whether child and parent generosity is correlated, (2) whether children are influenced by their parents when making sharing decisions and (3) whether parents model generosity to children. We observe no correlation of independently measured parent and child sharing decisions at this young age. Yet, we find that apart from those choosing an equal allocation of resources between themselves and another child, children adjust their behaviors to narrow the gap with their parent's or other adult's choice. We find that fathers, and parents of initially generous children, increase their sharing when informed that their child will be shown their choice.
\end{abstract}

JEL Classifications: C9, D1, D3

Keywords: field experiment, children, parents, transmission, social preferences, influence Corresponding author: Louis Putterman (Louis_Putterman@Brown.Edu).

We thank Aaron Sojourner, Felix Warneken, and participants at the Science of Philanthropy Initiative Annual Meeting, Annual Meeting of the Association for Research on Nonprofit Organizations and Voluntary Associations, Conference of the Society for the Advancement of Behavioral Economics and University of Minnesota seminar for helpful comments. We thank Amanda Chuan, Tristin Ganter, Akinori Kitsuki, Chien-Yu Lai, Dustin Pashouwer, Kevin Sokal and Mina Zhang for excellent research assistance. This project was funded by the John Templeton Foundation through the Science of Philanthropy Initiative. 


\section{Introduction}

While Adam Smith, widely regarded as the founder of economics, showed no naiveté about the importance of self-interest, he also asserted that human nature gives the typical person an "interest ... in the fortune of others, and render[s] their happiness necessary to him, though he derives nothing from it except the pleasure of seeing it" (Smith, 1759). The so-called "sentimental moralist" stance of Smith and his contemporary David Hume has been rightly identified as a precursor of modern discussions of innate human sociality in contemporary work by developmental psychologists (e.g., Warneken and Tomasello, 2009), evolutionary psychological theorists (e.g., Bloom, 2013), and students of behavior in social animals (e.g., DeWaal, 2009).

Related work has used experiments with young children to study whether the propensity to share or help is developed at a young age. Warneken (2013) and Warneken and Tomasello (2013) stage situations in which adults appear to get into difficulties in front of young children otherwise occupied at play, and find that children of ages 21 to 31 months spontaneously attempt to help. ${ }^{1}$ Within the economics literature, other-regarding behavior, or generosity, has been studied in standard dictator games, in which an individual is provided with an endowment and decides how to split it between himself and an anonymous receiver. A significant number of participants voluntarily allocate some amount to the recipient (for a survey of the literature, see Engel, 2011). Moreover, such studies suggest that the propensity to assist a genetically unrelated individual in some circumstances may be an evolved trait, as even very young children display other-regarding behavior (Harbaugh and Krause, 2000; Harbaugh et al., 2003; Fehr and Rockenbach, 2004; Kosfeld et al., 2005; Benenson et al., 2007).

\footnotetext{
${ }^{1}$ For example, children spontaneously help by picking up dropped objects or helping to open boxes or cabinets, doing so without encouragement or prior acknowledgment of the child's presence by the adult. Warneken and Tomasello (2013) find that neither presence nor encouragement of the child's parent alters the young child's tendency to proactively help the adult stranger.
} 
Investigating how other-regarding preferences are acquired among children may provide insight into the development of the motivation to give. This has immediate importance to the economics of philanthropy and may also have bearing on many other economic domains (for instance, those of political participation, tax compliance, and teamwork) in which inclinations towards pro-sociality and cooperation can play important roles. We propose that the respective roles played by genes and the environment can be explored by investigating the behavior of young children who are exposed to the influence of their parents. Parental influence by itself, however, cannot be taken as exogenous. Indeed, whether or not a parent will attempt to transmit certain social preferences to his or her child may be influenced not only by culture, socio-economic factors, and the parent's temperament, but also by the temperament of the child. For instance, a parent may make less effort to reinforce generosity in a child who appears naturally sympathetic, or may emphasize the importance of self-protection to one who seems too trusting (see Becker's (1974) 'rotten kid theorem' for related insights)

We develop a theoretical framework that sheds light on the developmental origins of social preferences by providing mechanisms through which parents transmit preferences for generosity to their children. Our theoretical model predicts that many parents will attempt to model generosity to their children, and that children will have a preference for mimicking parents, as utility of children is lowered by a large deviation from the norm set by the parent. It is relevant to consider how parental transmission of preferences operates from a theoretical standpoint, as several recent papers speak to this. Becker et al. (2014) provides one possible mechanism for parental modeling of preferences to children: parents want to teach children to be generous, so that children will provide for parents in their elderly years. Ottoni-Wilhelm and Zhang (2011) propose three parental motives for parents to transmit generosity: generosity makes one happy, generosity is a duty, and 
generosity is a part of one's identity. However, neither Becker et al. (2014) nor Ottoni-Wilhelm and Zhang (2011) provide a convincing mechanism through which generosity can be transferred. We propose that one mechanism is through modeling behavior, and provide a theoretical basis and empirical test of this mechanism.

Then, we conduct an artefactual field experiment with 147 preschool-aged children - ages $3-5^{2}$ - and their parents. Since related work has shown that children's generosity is low at the age of 3-4 and increases as children grow up (e.g., Fehr et al., 2008), our experiment is designed to target children at this key developmental stage. In the experiment, children and parents separately play a series of dictator games, choosing how much of a resource to keep and how much to share with an anonymous match (we match children to an anonymous other child, and parents to an anonymous other adult). In a series of treatments, we also measure whether parents change their behavior when they know their child may see their dictator game decisions prior to their child making his or her own decision, and whether children change their behavior when they observe how their mother, father, or another adult shared.

Our main results are that (1) there is virtually no correlation between the uninfluenced sharing decisions of preschoolers and of their parents; (2) change of parental behavior when the parent knows the child will see his or her choice is detected mainly in parents of those children who are relatively generous in their initial, uninfluenced choice; and (3) there is strong evidence that preschoolers whose initial decision was either more or less generous than an equal split adjust their sharing decision in response to an observed parental or other adult choice in a similar setting. Interestingly, children respond similarly to sharing behavior of adults - whether it is a parent or an unknown adult.

\footnotetext{
${ }^{2}$ Almost all children were ages 3-5 during the experiment. One child turned 6 a month prior to the experiment. In the parlance of Harrison and List (2004), our experiment should be classified as an artefactual field experiment.
} 
The remainder of the paper begins with our review of related literature in Section 2. We introduce our theoretical framework in Section 3. We describe our experimental setting and design in Section 4. Section 5 presents our results and analysis. Section 6 provides our concluding discussion.

\section{Related Literature}

While economics is often characterized by its assumption that human behavior is motivated by self-interest, a growing empirical literature has provided evidence consonant with models of other-regarding behavior, or generosity, amongst children and adults. Within other literatures, the work of Warneken (2013) and Warneken and Tomasello (2013) suggests that a toddler experiences a natural inclination to help even before she is able to decode an adult's pro-social encouragement. It is possible that helping behaviors emerge over time in response to rewarding and punishing in the home, but evidence with which to evaluate that conjecture rigorously is thus far inadequate. The hypothesis that a child's inclination to help results at least in part from an innate disposition is thus impossible to reject, at present. Indeed, there is evidence from identical twin studies that variation in the degree of pro-social, cooperative or altruistic behavior is heritable (Wallace et al., 2007; Cesarini et al., 2008).

There is, nevertheless, every reason to suppose that a child of 21 months has been exposed to messages from parents relevant to the choices we study, whether or not accompanied by admonitions, punishments and rewards. An early study of parental influence on child altruism by Hoffman (1975) suggests that altruistic fifth graders have at least one (usually same-sex) parent who communicates altruistic values and a parent (often opposite-sex) who uses victim-centered 
discipline techniques suggesting reparation and apology. Frequent parental expressions of affection also contribute to child altruism. ${ }^{3}$

Recent views on the human propensity to conformism suggest that children are eager to copy even in the absence of explicit incentives. This runs contrary to early behavioral psychologists, who thought parental influence requires punishments and rewards. Harris (2012) reports experiments in which children or chimpanzees are given demonstrations of how to accomplish a task to which a materially superfluous element - a manipulation of the object that lacks instrumental utility for the goal in question - has been added. The chimpanzees become adept at accomplishing the task but quickly discard the unneeded step, whereas the children faithfully include that step in their performances even when not watched and despite showing clear cognitive awareness that the physical necessity of the step is at a minimum unclear. The takeaway is that humans have a strong predisposition to try to understand "how things are done" in the social group they identify with, and to act accordingly. These findings, as Harris notes, are consistent with the role accorded to the "conformist" impulse in the theory of culture proposed by Boyd and Richerson (2005).

Disentangling the respective roles of words and of actions has been a topic of research in several disciplines. Rushton (1975) exposed 140 seven to eleven year old children to a combination of moral preaching and moral behavior by an adult role model (introduced in a school setting as a possible future teacher at the school), and studied the effect on the children's decisions about donating to needy individuals both immediately after the interaction, and eight weeks later. Action modeling was found highly effective both in the immediate and the follow-up situations, whereas preaching proved effective in the follow-up but not in the immediate observations. From

\footnotetext{
${ }^{3}$ Zumbühl et al. (2013) provide evidence that intensity of parental investment affects the degree to which parental attitudes are transmitted.
} 
later research, however, Rushton concluded that children learn generosity not by listening to what a role model says, but by observing what that person does—a finding of particular relevance to our study.

A number of studies have found that children's tendency to share or to display other signs of concern for fairness increase with age. Fehr, Bernhard and Rockenbach (2008) asked 229 children between 3 and 8 years of age to make three choices affecting resources (candies) received by self and by another child. Most pertinently, each child had to choose between a 2 for self, 0 for other allocation, and a 1, 1 allocation. While only $8.7 \%$ of $3-4$ year olds chose the 1,1 allocation, $22 \%$ of $5-6$ year olds did so, rising to $45 \%$ of $7-8$ year olds. Increasing pro-sociality with age is also found by Bar-Tal, Raviv and Leiser (1980), Benenson, Pascoe and Radmore (2007), Devanath (2010) and Fehr, Rützler and Sutter (2011). However, the finding of Fehr et al. (2008) shows that increased sharing with age only applies when the recipient is a child in the same school; about $23 \%$ of $3-4$ year olds chose 1, 1 when the recipient was said to attend a different school, and the amount shared actually fell with age, in the other school condition. Houser, Montinari and Piovesan (2012) finds that the presence of watching peers increases pro-sociality at age 9 and higher, but not at younger ages.

We are not the first to base an experiment on sharing behavior in preschoolers in the setting of a dictator game (Gummerum et al., 2010; List and Samak, 2013). List and Samak (2013) investigated the presence of altruistic or warm glow giving among preschoolers, and concluded that giving is primarily driven by pure altruism at this age. Whether children of this age may recognize neediness in others and discriminate in their sharing accordingly was studied by Zinser, Perry and Edgar (1975). The authors gave children between 4 and 6 years old an opportunity to share candies with an individual whose relative affluence or poverty was indicated by a picture of 
the type of house they lived in (similar to our study) and a brief story. They find more sharing with poorer recipients and attribute this to empathy.

Parental influence on the sharing decision has also been investigated in work conducted concurrently with ours. Blake, Corbit, Callaghan and Warneken (2014) study parental modeling and influence on sharing by 3 to 8 year old children in India and the United States, finding some evidence of influence increasing with child age and concluding that what parents attempt to teach is culture-specific. Bauer, Chytilová and Pertold-Gebická (2014) investigate the correlates of parental background on children's sharing behavior and find a correlation with parental education level.

Bauer et al. (2014) characterize the degree of other-regarding orientation in children ages $4-12$ on the basis of four games and tests and find substantial heterogeneity, some of it related (positively) to parental socio-economic status and age, similar to Benenson et al.'s (2007) dictator game findings. Cipriani et al. (2013) conduct public goods games with children ages preschool through $6^{\text {th }}$ grade and their parents, and measure the degree of correlation between generosity of parents and their children. The authors find no correlation between parents' and children's decisions, perhaps because children have many other environmental and schooling influencers on their generosity. This paper is closely related to our own investigation of the correlation between parents' and their preschool children's giving in the dictator game.

Although related studies exist, our study of the impact of parental choices on preschoolers is novel in a number of respects, including its consideration of changes in parental choices in the presence of a modeling opportunity and changes in child choices after versus before exposure to such modeling. We are unaware of past findings or theoretical reasoning that would lead to highly specific predictions. 


\section{Theoretical Framework}

We set forth a model that provides a framework for analyzing the relationship between parents' and their children's generosity in relationship to our experiment. In our setup, otherregarding preferences, or preferences towards generosity, are revealed through sharing decisions. Specifically, parents and children have opportunities to share an endowment with an anonymous match. While the experimental conditions include variation in the neediness of the recipient and in whether it is the parent's or another adult's actions that the child observes, we direct our modeling to giving decisions and the parent-child nexus, discussing other dimensions less formally to avoid notational clutter. We start by considering the maximization problems for a parent and his or her child before the exercise of any influence by the parent in the experiment and when the parent knows her decision will not be shown to her child. We refer to these as the Uninfluenced and No Show condition, respectively. Next, we model the child's utility maximization problem after the exercise of parental influence (we call this the Influenced condition). Finally, we examine the parent's choice of sharing in the condition in which her decision will be shown to her child (we call this the Show Condition).

We begin by denoting the parent's utility function as

$$
U_{p}\left(g_{p}, c_{p}\right)+V_{p}\left(g_{c}, c_{c}\right)
$$

where $g_{p}$ is the amount the parent gives in the experiment, and $c_{p}$ is the parent's consumption, the latter being determined both by the amount she does not choose to give away in the experiment and by her outside resources (income). Thus, we define $U_{p}\left(g_{p}, c_{p}\right)$ as the parent's private utility and assume that it is quasi-concave in $g_{p}$ and $c_{p} \cdot g_{c}$ is the amount the child gives in the experiment, and $c_{c}$ is child's consumption. Then, $V_{p}\left(g_{c}, c_{c}\right)$ is the parent's utility from the child's 
behavior, and it is assumed to be quasi-concave in $g_{c}$ and $c_{c}$. With respect to $g_{c}$, this assumption may reflect the parent's own altruism. $g_{p}$ also reflects the parent's sense of duty or of adherence to an ideal or norm (Ottoni-Wilhelm \& Zhang, 2011) and the parent's interest in encouraging altruism from which she will be a future beneficiary (Becker, Murphy, \& Spenkuch, 2014). Note, too, that the valuation of $g_{p}$ and $g_{c}$ could vary with the parent's perception of the beneficiary's neediness, with a higher valuation presumably attaching to gifts targeted to a poorer recipient, but we omit explicit notation as the matter is intuitive and as this dimension of variation plays a minor role in our experiment. ${ }^{4}$

We denote the child's utility as the following:

$$
\begin{gathered}
U_{c}\left(g_{c}, c_{c}\right)-\alpha \cdot \mathrm{I}(\text { observe parent's choice }) \cdot \mathrm{f}\left(g_{c}, g_{p}\right) \\
\alpha>0 \\
\mathrm{f}\left(g_{c}, g_{p}\right)=g_{c}-g_{p}, \forall g_{c} \geq g_{p} \\
\mathrm{f}\left(g_{c}, g_{p}\right)=g_{p}-g_{c}, \forall g_{c}<g_{p}
\end{gathered}
$$

where $c_{c}$ is the child's consumption and I(observe parent's choice) is an indicator function for the child observing the parent's choice in the Influenced case, discussed later. We also assume that $U_{c}\left(g_{c}, c_{c}\right)$ is quasi-concave in $g_{c}$ and $c_{c}$, and the marginal utility of both $g_{c}$ and $c_{c}$ in $U_{c}\left(g_{c}, c_{c}\right)$ is positive. To avoid notational clutter, we omit notation to indicate possible differences at individual or family level. However, individual differences in the exact shapes of the $U$ and $V$ functions, representing different relative valuations of consumption versus giving, may well exist, and we comment on this further in our discussion below.

\footnotetext{
${ }^{4}$ We leave open whether the decision-maker's valuation of giving is entirely driven by the recipient's need, as in models of pure altruism, or whether the act of giving is valued in itself for warm-glow or identity reasons.
} 
In the Uninfluenced and No Show conditions, where the child does not observe the parent's choice, the parent and child maximize their utility independently of social influence considerations. The parent maximizes (1) with respect to $g_{p}$, thereby determining also $c_{p}$. The parent knows that the child will not be shown the decision, so we can treat the parent as assuming that $g_{c}$ and $c_{c}$ will be unaffected, ${ }^{5}$ and accordingly the parent's maximization problem is equivalent to:

$$
\max _{g_{p}} U_{p}\left(g_{p}, c_{p}\right)
$$

The parent maximizes only his or her private utility, facing the following constraints:

$$
\begin{gathered}
c_{p}+g_{p}=r+M_{p} \\
0 \leq g_{p} \leq r
\end{gathered}
$$

The first constraint is the parent's budget constraint, where $r$ is the experimental endowment and $M_{p}$ is resources available to the parent from outside the experiment. ${ }^{6}$ The second constraint in conjunction with the first states that the parent can share only the experimental endowment, but not other resources. Suppose that this maximization problem has an interior solution, $g_{p}^{*}$. Then:

$$
U_{p g}\left(g_{p}^{*}, r+M_{p}-g_{p}^{*}\right)=U_{p c}\left(g_{p}^{*}, r+M_{p}-g_{p}^{*}\right)
$$

The left hand side of the equation represents the marginal utility of $g_{p}$, and the right hand side is the marginal cost of $g_{p}$ in terms of forgone utility from consumption. By assuming that $g_{p}$ and $c_{p}$ are normal goods, $\frac{\partial g_{p}^{*}}{\partial M_{p}}>0$. In sum, in the No Show condition the parent's optimal

\footnotetext{
${ }^{5}$ We ignore the possibility that the parent anticipates verbally telling the child of the decision, that she doubts the experimenter's statements that the decision will not be shown to the child, and so on.

${ }^{6}$ To keep the model simple, saving and other uses of resources are ignored or collapsed into $c_{c}$, and for purposes at hand, we can leave unspecified whether $M_{p}$ should be thought of as average weekly disposable income or some other indicator of available resources.
} 
choice entails that generosity increases with income. Individual differences in $U$ functions reflecting larger or smaller degrees of altruism, sense of duty, etc., may also cause privately optimal $g_{p}$ to vary, holding income constant.

Similarly, in the Uninfluenced condition, the child is not affected by his or her parent's choice in the experiment, and therefore the child's maximization problem is:

$$
\max _{g_{c}, c_{c}} U_{c}\left(g_{c}\right)
$$

The child's constraints are similar to those of the parent:

$$
\begin{gathered}
c_{c}+g_{c}=s+M_{c} \\
0 \leq g_{c} \leq s
\end{gathered}
$$

where $s$ is the child's experimental endowment (6 stickers) and $M_{c}$ is child's "income" outside the game as the child perceives it, for example in terms of his or her stickers and other toys at home. The child's optimal choice, $g_{c}^{*}$, must satisfy:

$$
U_{c g}\left(g_{c}^{*}, s+M_{c}-g_{c}^{*}\right)=U_{c c}\left(g_{c}^{*}, s_{c}+M_{c}-g_{c}^{*}\right)
$$

As in the case of the parent, $\frac{\partial g_{c}^{*}}{\partial M_{c}}>0$, so that generosity increases with the child's perceived availability of resources or "income."

The degrees of parent and child generosity may be correlated because of correlation between their respective incomes (resources), and possibly because of similarity in their utility functions. The child's utility function may resemble the parent's for genetic reasons, or due to the influence of parental modeling and behavior outside the lab.

Suppose that in society parents' incomes (resources) are positively correlated with the resources that their children perceive themselves to have, that is, $\operatorname{Cov}\left(M_{p}, M_{c}\right)>0 .^{7}$ Then, if

\footnotetext{
${ }^{7}$ An alternative way of modeling this relationship could make the child's resources depend on the parent's by way of the parent's consumption choice and generosity toward the child. Such constraints may be loosened, however,
} 
parents and children have the same utility function, $\operatorname{Cov}\left(g_{p}^{*}, g_{c}^{*}\right)>0$. The intuition behind this is straightforward. Consider two families with identical utility functions for parents and children but in one family incomes are higher for both parents and children than in the other family. Then, the family with lower $\left(M_{p}, M_{c}\right)$ will choose lower $\left(g_{p}^{*}, g_{c}^{*}\right)$, and the one with higher $\left(M_{p}, M_{c}\right)$ will choose higher $\left(g_{p}^{*}, g_{c}^{*}\right)$. This is a direct result of the income effect caused by the assumption of generosity and consumption being normal goods. If parent and child tastes are also correlated, or indeed even if tastes are entirely uncorrelated, we nonetheless can predict:

$$
\operatorname{Cov}\left(\frac{U_{p g}}{U_{p c}}\left(g_{p}, c_{p}\right), \frac{U_{c g}}{U_{c c}}\left(g_{c}, c_{c}\right)\right)>0, \forall\left(g_{p}, c_{p}, g_{c}, c_{c}\right)
$$

This condition states that parents' and children's MRS between generosity and private consumption are positively correlated. This means that, on average, a more generous parent (compared to other parents in the society) has a more generous child (compared to other children in the society). If the correlation condition above holds, it can be shown that on the assumptions presented thus far there should be a positive correlation between parents' and children's sharing decisions in the Uninfluenced case. We thus have

Hypothesis 1 (family/inheritance hypothesis): The sharing decisions of parents in the No Show condition are positively correlated with the uninfluenced experimental sharing decisions of their children in the Uninfluenced condition.

Next, we ask how a child's generosity may be influenced by parental behavior observed by the child, including that in the experiment's Show condition. On the basis of the literature reviewed earlier, we propose that children will tend to adjust their sharing decisions based on the

because the child obtains some resources from the other parent, from grandparents, from the school, and so on; also, a degree of freedom is introduced by defining $M_{c}$ as a perceived quantity. We thus assume no more than positive covariance between $M_{p}$ and $M_{c}$. 
sharing decisions they observe their parents to make. The "nurture" part of the argument for similarity in parent and child utility functions is grounded in such a tendency to repeatedly emulate behavior until it is enshrined in the utility function. Note, however, that we explicitly model only the emulative behavior, treating both the parent's and the child's utility functions as givens.

To explore this emulation mechanism, we specify an additive version of the parent's utility function in equation (1):

$$
\begin{aligned}
& U_{p}\left(g_{p}, c_{p}\right)+V_{p}\left(g_{c}, c_{c}\right)=U_{p}^{g}\left(g_{p}\right)+U_{p}^{c}\left(c_{p}\right)+V_{p}^{g}\left(g_{c}\right)+V_{p}^{c}\left(c_{c}\right) \\
& U_{c}\left(g_{c}, c_{c}\right)=U_{c}^{g}\left(g_{c}\right)+U_{c}^{c}\left(c_{c}\right) \\
& \mathrm{U}^{\prime}(\cdot)>0, \mathrm{U}^{\prime \prime}(\cdot)<0 \\
& \mathrm{~V}^{\prime \prime}(\cdot)<0
\end{aligned}
$$

We similarly specify an additive version of the child utility function in equation (1) when the child observes the parent's choice $\hat{g}_{p}($ i.e., $\mathrm{I}($ See parent's choice $)=1)$ :

$$
\begin{gathered}
U_{c}^{g}\left(g_{c}\right)+U_{c}^{c}\left(c_{c}\right)-\alpha \cdot \mathrm{f}\left(g_{c}, \hat{g}_{p}\right) \\
\alpha>0 \\
\mathrm{f}\left(g_{c}, \hat{g}_{p}\right)=g_{c}-\hat{\mathrm{g}}_{p}, \forall g_{c} \geq \hat{g}_{p} \\
\mathrm{f}\left(g_{c}, \hat{g}_{p}\right)=g_{p}-\hat{g}_{p}, \forall g_{c}<\hat{g}_{p}
\end{gathered}
$$

The last two inequalities mean that the child incurs disutility from making a decision that is different from the parent's. Accordingly, the child may sacrifice some of the direct utility associated with her $U_{c}$ terms in order to reduce the size of the gap. To make a comparison with the Uninfluenced condition, we define $g_{c}^{*}$ as the child's Uninfluenced optimal choice derived from: 


$$
-U_{c}^{c}\left(s+M_{c}-g_{c}^{*}\right)+U_{c}^{g},\left(g_{c}^{*}\right)=0^{8}
$$

The left hand side is the child's marginal utility of $g_{c}$ at $g_{c}=g_{c}^{*}$. We now discuss three possibilities for how a child's choice may be affected by the parent's choice. First, consider the possibility that the parent shares in the Show condition more than the child shares in the Uninfluenced condition, $\hat{g}_{p}>g_{c}^{*}$. In this case the child's marginal utility of $g_{c}$ at $g_{c}=g_{c}^{*}$ is:

$$
\text { (9) } \quad-U_{c}^{c \prime}\left(s+M_{c}-g_{c}^{*}\right)+U_{c}^{g \prime}\left(g_{c}^{*}\right)+\alpha>0
$$

This means that the marginal utility of $g_{c}$ at $g_{c}=g_{c}^{*}$ is still positive so the child can get greater utility by increasing his or her generosity. When $\hat{g}_{p}>g_{c}^{*}$, the child's optimal choice (denoted as $\hat{g}_{c}^{*}$ ) has the following property (FOC):

$$
\begin{gathered}
-U_{c}^{c^{\prime}}\left(s+M_{c}-\hat{g}_{c}^{*}\left(\hat{g}_{p}\right)\right)+U_{c}^{g \prime}\left(\hat{g}_{c}^{*}\left(\hat{g}_{p}\right)\right)+\alpha=0 \\
\hat{g}_{p} \geq \hat{g}_{c}^{*}\left(\hat{g}_{p}\right)>g_{c}^{*}
\end{gathered}
$$

The inequality above implies that the child should not adjust too much to the parent's choice by choosing too large a $g_{c}$ Were the child to "over-adjust" and choose $g_{c}>\hat{g}_{p}$, he would not only deviate a lot from $g_{c}^{*}$, but would bear $-\alpha \cdot \mathrm{f}\left(g_{c}, \hat{g}_{p}\right)$ as an additional cost due to not conforming to the parent's decision.

A similar analysis applies to the case in which $\hat{g}_{p}<g_{c}^{*}$ :

$$
-U_{c}^{c \prime}\left(s+M_{c}-g_{c}^{*}\right)+U_{c}^{g,}\left(g_{c}^{*}\right)-\alpha<0
$$

But in this case maximization condition (10) will hold with

$$
\hat{g}_{p} \leq \hat{g}_{c}^{*}\left(\hat{g}_{p}\right)<g_{c}^{*}
$$

\footnotetext{
${ }^{8}$ Note that (8) is a simplified version of (4). Whereas the latter assumes a generalized $U_{p}\left(g_{p}, c_{p}\right)$ function, the former uses the more specific assumption that $U_{p}\left(g_{p}, c_{p}\right)=U_{p}^{g}\left(g_{p}\right)+U_{p}^{c}\left(c_{p}\right)$ which means that utility from $g_{p}$ and $c_{p}$ are separable.
} 
It is optimal for the child to reduce the size of the difference in sharing choice relative to that of his or her parent, but the adjustment in generosity will not necessarily result in an identical level of generosity to that of the parent.

Finally, there is the case in which $\hat{g}_{p}=g_{c}^{*}$. In this case, $\hat{g}_{c}^{*}\left(\hat{g}_{p}\right)=g_{c}^{*}$ because the FOC still holds at this point. Thus, the child has no incentive to deviate from his or her optimal choice in the Uninfluenced condition.

From all cases above, we know that when the child sees that his or her parent's choice is different from what he or she wants to choose in the Uninfluenced condition, the child tends to adjust his or her choice toward the parent's choice, but the emulation will in general be imperfect. This brings us our second hypothesis:

Hypothesis 2 (emulation hypothesis): children adjust their sharing decisions to reduce the difference between their sharing and the observed sharing decisions of their parents.

Here, an additional remark about emulation and conformism is in order. While it assumes that a young child derives disutility from having a large gap in behavior relative to a parent, our model is silent about whether children will emulate others, for instance other adults. The general human tendency towards emulation mentioned in the literature review suggests that they may well do so, although closeness of the parent-child bond might incline us to suppose that the emulative tendency will be stronger with respect to a parent. Our experimental set-up makes it a simple matter to observe whether there is a difference between emulation of parent and of other adult, and we will obtain and discuss evidence on the matter in the next section. Our model focuses on the parent child interaction, leaving it to the data to speak to similarity or difference of emulative tendency when observing other adults. 
Finally, we turn to the question of how parents make their sharing decision when they know that it will be observed by their children (the Show condition). We propose that the decision is driven by the desire to model a behavior - that is, parents will tend to show their children behaviors that they would like their children to emulate. However, we leave open the possibility that parents give weight to both the abstract ideal of generosity they hold to or would like their child to have, as well as to the subjective cost they believe following that ideal would impose on their child, whose direct utility is always a concern owing to parental altruism. Thus, our model provides a prediction for changes in parental behavior depending on whether or not the information about the parent's behavior is shared with his or her child.

The discussion leading up to Hypothesis 2 suggests that the parent can use backwardinduction to solve the child's maximization problem and predict the child's choice $\hat{g}_{c}^{*}\left(\hat{g}_{p}\right)$. This problem is:

$$
\max _{\hat{g}_{p}} U_{p}^{g}\left(\hat{g}_{p}\right)+U_{p}^{c}\left(r+M_{p}-\hat{g}_{p}\right)+V_{p}^{g}\left(\hat{g}_{c}^{*}\left(\hat{g}_{p}\right)\right)+V_{p}^{c}\left(s+M_{c}-\hat{g}_{c}^{*}\left(\hat{g}_{p}\right)\right)
$$

The FOC for an interior solution of this problem is:

$$
\begin{gathered}
(12) \quad U_{p}^{g \prime}\left(\hat{g}_{p}^{*}\right)-U_{p}^{c \prime}\left(r+M_{p}-\hat{g}_{p}^{*}\right) \\
+\left[V_{p}^{g \prime}\left(\hat{g}_{c}^{*}\left(\hat{g}_{p}^{*}\right)\right)-V_{p}^{c \prime}\left(s+M_{c}-\hat{g}_{c}^{*}\left(\hat{g}_{p}^{*}\right)\right)\right] \hat{g}_{c}^{* \prime}\left(\hat{g}_{p}^{*}\right)=0
\end{gathered}
$$

From Hypothesis 2, we know that $\hat{g}_{c}^{* \prime}\left(\hat{g}_{p}\right) \geq 0$ (children tend to emulate their parents). How the parent changes his or her choice when the choice is observed by his or her child depends on the sign of $\left[V_{p}^{g \prime}\left(\hat{g}_{c}^{*}\left(\hat{g}_{p}\right)\right)-V_{p}^{c^{\prime}}\left(s+M_{c}-\hat{g}_{c}^{*}\left(\hat{g}_{p}\right)\right)\right]$ around $\hat{g}_{p}=g_{p}^{*}$, where $g_{p}^{*}$ is the solution derived from equation (3).

To examine the case of a parent who cares about his or her child's sharing, we define

$$
V_{p}^{g}\left(g_{c}\right)+V_{p}^{c}\left(c_{c}\right)=\mathrm{X}\left(g_{c}\right)+\beta\left[U_{c}^{g}\left(g_{c}\right)+U_{c}^{c}\left(c_{c}\right)\right]
$$




$$
\begin{gathered}
\beta \geq 0 \\
X^{\prime}(0) \geq 0 \\
\exists g_{c}^{* *} \in[0, s], s t . X^{\prime}\left(g_{c}^{* *}\right)=0 \\
X^{\prime \prime}\left(g_{c}\right)<0
\end{gathered}
$$

Here, function $\mathrm{X}\left(g_{c}\right)$ captures the parent's additional utility from the child's generosity, and $g_{c}^{* *}$ is the level of generosity the parent holds as ideal independent of the child's direct short-run utility considerations. ${ }^{9}$ The term $\beta\left[U_{c}^{g}\left(g_{c}\right)+U_{c}^{c}\left(c_{c}\right)\right]$ takes into account the child's immediate utility as such, with $\beta$ indicating the weight that the parent's places on it. If the parent does not care about the child's generosity per se $\left(\mathrm{X}\left(g_{c}\right)=0, \forall g_{c}\right)$, then the parent's FOC in the Show condition is:

$$
+\beta\left[U_{c}^{g \prime}\left(\hat{g}_{c}^{*}\left(\hat{g}_{p}^{*}\right)\right)-U_{c}^{c^{\prime}}\left(s+M_{c}-\hat{g}_{c}^{*}\left(\hat{g}_{p}^{*}\right)\right)\right] \widehat{g}_{c}^{* \prime}\left(\hat{g}_{p}^{*}\right)=0
$$

We cannot determine the sign of $U_{c}^{g \prime}\left(\hat{g}_{c}^{*}\left(\hat{g}_{p}\right)\right)-U_{c}^{c^{\prime}}\left(s+M_{c}-\hat{g}_{c}^{*}\left(\hat{g}_{p}\right)\right)$ at $\hat{g}_{p}=g_{p}^{*}$. It is possible that the child's utility function induces a more selfish decision in the Uinfluenced condition than the No Show condition decision of the parent, in which case the parent's altruism leads her to behave more selfishly in the Show condition. However, by the same reasoning, parents can also be more generous in the Show condition, in particular when their child's utility function causes the child to be more generous than the parent. Thus, when the parent has no ideal of altruism to impart $\left(\mathrm{X}\left(g_{c}\right)\right.$ is uniformly 0$)$, we can make no unambiguous prediction.

Next, consider the case in which $\mathrm{X}\left(g_{c}\right)>0$ for some $g_{c}>0$. For such parents, $\mathrm{X}^{\prime}\left(g_{c}\right)>$ 0 when $g_{c}=0$, but there may be a $g_{c}^{* *}<s$ at which $\mathrm{X}^{\prime}\left(g_{c}^{* *}\right)=0$. When the child's giving exceeds

\footnotetext{
${ }^{9}$ Whether the parent believes such generosity will benefit the child in the long term, it is an absolute moral or religious ideal she feels obligated to convey to the child, or what other factors can account for such an ideal, are open to interpretation.
} 
$g_{c}^{* *}$, any additional generosity by the child becomes a bad in and of itself from the parent's standpoint, $\mathrm{X}^{\prime}\left(g_{c}\right)<0$. However, there may be an offsetting willingness to indulge any innate generosity on the child's part via the $\beta$ term in (13). In this range (which for some may begin at a quite low value), the parent judges it unwise or excessive to indulge in generosity and may think that it is better to make the child learn how to "look out for himself." In view of eq. (13) and our assumptions about the $\mathrm{X}\left(g_{c}\right)$ function, we can derive the parent's FOC in Show condition as:

$$
U_{p}^{g}\left(\hat{g}_{p}^{*}\right)-U_{p}^{c \prime}\left(r+M_{p}-\hat{g}_{p}^{*}\right)
$$$$
+\left\{\beta\left[U_{c}^{g,}\left(\hat{g}_{c}^{*}\left(\hat{g}_{p}^{*}\right)\right)-U_{c}^{c^{\prime}}\left(s+M_{c}-\hat{g}_{c}^{*}\left(\hat{g}_{p}^{*}\right)\right)\right]+X^{\prime}\left(\hat{g}_{c}^{*}\left(\hat{g}_{p}^{*}\right)\right)\right\} \hat{g}_{c}^{* \prime}\left(\hat{g}_{p}^{*}\right)=0
$$

To simplify the discussion, we consider the following two cases. The first is that of parents who have $X^{\prime}\left(\hat{g}_{c}^{*}\left(g_{p}^{*}\right)\right)<0$, that is, their ideal of child giving $g_{c}^{* *}$ is less than the amount they give when not watched, $g_{p}^{*}$. Such a parent, perhaps relatively rare, has a soft spot for charity in the No Show condition, but believes it best to convey more self-regarding values to her child so he will fare better in a harsh world. These parents are more likely to have $\left\{\beta\left[U_{c}^{g,}\left(\hat{g}_{c}^{*}\left(\hat{g}_{p}\right)\right)-\right.\right.$ $\left.\left.U_{c}^{c \prime}\left(s+M_{c}-\hat{g}_{c}^{*}\left(\hat{g}_{p}\right)\right)\right]+\mathrm{X}^{\prime}\left(\hat{g}_{c}^{*}\left(\hat{g}_{p}\right)\right)\right\}<0$ around $\hat{g}_{p}=g_{p}^{*}$, and thus to choose $\hat{g}_{c}^{*}<g_{p}^{*}$. We cannot infer this with certainty from $\mathrm{X}^{\prime}\left(\hat{g}_{c}^{*}\left(g_{p}^{*}\right)\right)<0$ alone however, because if the parent believes her child to be naturally more generous than herself, the altruism represented by the term containing $\beta$ could conceivably tip the outcome in the other direction, rendering $\left\{\beta\left[U_{c}^{g^{\prime}}\left(\hat{g}_{c}^{*}\left(\hat{g}_{p}\right)\right)-U_{c}^{c^{\prime}}\left(s+M_{c}-\hat{g}_{c}^{*}\left(\hat{g}_{p}\right)\right)\right]+\mathrm{X}^{\prime}\left(\hat{g}_{c}^{*}\left(\hat{g}_{p}\right)\right)\right\}>0$ at $\left.\hat{g}_{p}=g_{p}^{*}\right\}$ and causing the parent's giving to increase in the Show condition, despite the parent's ideal judgment (X function). The converse argument can be made for parents whose ideal of generosity for their child exceeds their own behavior in the No Show condition, and who therefore have $\left(\mathrm{X}^{\prime}\left(\hat{g}_{c}^{*}\left(g_{p}^{*}\right)\right)>0\right)$ : these parents are more likely to choose a higher sharing decision in the Show condition than in the No 
Show condition, although again the influence of the altruism term (containing $\beta$ ) could either offset or reinforce this tendency.

Deriving an overall prediction for how parents change their behavior in the Show versus No Show condition is difficult when parental ideals represented by the $\mathrm{X}$ functions, and beliefs about their children's $U$ functions, may differ from one another and are not observable. However, we can derive a hypothesis about parental behavior in the Show condition of our experiment if we assume that (i) parents' guesses about their children's $U$ functions (including their guesses as to how much past parental modeling has or has not influenced those functions) are not worse than random, and that (ii) parents' private choices (such as their choice in No Show condition) are typically biased towards self-interest, i.e., $g_{p}^{*} \leq g_{c}^{* *} \cdot{ }^{10}$ The second assumption implies that usually $\mathrm{X}^{\prime}\left(\hat{g}_{c}^{*}\left(g_{p}^{*}\right)\right)>0$ ) for parents inclined to model generosity when watched in and out of the lab, while the first assumption means that the parents of children inclined to behave generously will be led to act more generously in the Show condition by the parental altruism $(\beta)$ argument in (13). These assumptions and the framework of equation (13) lead us to:

Hypothesis 3 (teaching/role modeling hypothesis): Parents who change their decision from the No Show to Show condition are more likely to increase than to decrease sharing. Parents of children who are more generous in the Uninfluenced condition are more likely to increase their sharing in the Show condition. This is due to the influence - via their altruism towards their childof their belief that the child's preferences favor generosity. ${ }^{11}$

\footnotetext{
${ }^{10}$ This isn't meant to rule out the occasional parent who is more generous when unwatched, but only to say that the parent who is more generous when watched appears likely to be more typical.

${ }^{11}$ Note that the hypothesis is consistent with but need not assume that the parent's past moral modeling has in fact influenced the child's generosity by the age we are considering. We will indeed not find support for such influence in our experimental data.
} 
Before turning to our experimental design and results, it is important to note that while the model presented in this section focuses on anticipated and actual emulation of parent by child, it does not explicitly address the evolution of the child's preferences as such. A more ambitious model would allow the child's $U$ function to change gradually with repeated opportunities to emulate the parent's modeling, and the parent would take these long-term effects on $U_{c}$ into account when selecting her behavior. Our model is therefore merely a simplified way of telescoping concerns with longer-term effects, but fleshing this dimension out explicitly is beyond the scope of our paper.

\section{Experimental Environment}

\subsection{Procedures}

The series of dictator games was conducted at the Chicago Heights Early Childhood Center (CHECC) program on Saturday, November 5, 2011. The CHECC was launched in August 2010 and serves as a 'laboratory' for experiments of this sort, as well as for studying the impacts of alternative preschool programming on child outcomes. ${ }^{12} \mathrm{CHECC}$ is in Chicago Heights, IL, which is a predominately low-income area, with a median annual income of around $\$ 43,000$ and a large minority population. Area families are eligible to participate in CHECC if they have children between the ages of 3-5.

For this experiment, we sent recruitment letters to 700 households who have children ages 3-5 and participate in CHECC (about 300 mother-child and 500 father-child pairs). We did not inform participants of the nature of the experiment, and participants were accustomed to receiving

\footnotetext{
${ }^{12}$ The CHECC was called the Griffin Early Childhood Center (GECC) between 2010-2011 and was renamed to CHECC in 2012. The program is located in Chicago Heights, IL.
} 
other invitations to come to the center on weekends (for example, to fill out demographic surveys or participate in other, unrelated experiments). 165 parent-child pairs participated in the experiment; and we have usable data (including demographics) for 147 pairs.

Parents and children participated in the experiment separately. Upon arriving to the experimental session, parents were immediately escorted to the parent experiment room while children were escorted to one of the child experiment rooms (see Appendix Figure 1). In the parent experiment room, during each session the experimenter read instructions out loud while 5-20 participants followed along on their instruction sheets. For Spanish-speaking parents, instructions were translated in real-time into Spanish using headphones. Then, parents made decisions in private using paper and pencil. Decision sheets were collected following the experiment.

In the child experiment rooms, children participated one-on-one with an experimenter either in English or in Spanish, depending on the child's primary language. The experimenter read the instructions out loud and the child listened. For children, a series of pictures were also displayed to aid in understanding the instructions.

Participation took approximately 45 minutes and parents received a \$15 show-up payment at the end of the study. Parents and children also received the money and stickers that they chose to keep for themselves at the end of the experiment (up to $\$ 24$ for parents and up to 18 stickers for each child). All monetary payments were disbursed in cash immediately at the end of the experiment, and children took their stickers with them when leaving. Key in the implementation procedures was that receivers in the dictator games, other families who had not participated in the experiment, actually received the amounts given in the dictator games. Recipients were anonymous to the dictators, whereby parents were matched with adult recipients while children were matched with child recipients. 


\subsection{Experimental Design}

The main goals of our experiment were to investigate (1) the correlation between parent and child giving, (2) the role of parent teaching/role modeling in parent giving, and (3) child emulation of parent giving. Giving is our measure of generosity, and we obtain it from a series of dictator games with both parents and children. While we focus on the cases of parent and child giving to poor individuals and on the interaction between those decisions, conditions in which each gives to less poor individuals and in which the child is shown the action of an adult other than the parent are included in the design and permit additional comparisons. Table 1 summarizes the experimental design; full experimental instructions are presented in Appendix I (parents) and II (children).

All adults acted as dictators in four games matched with four different anonymous receiver adults. Each adult received an endowment of $\$ 6$ each time and chose how to divide it between himself or herself and the receiver. In each game, subjects received six one dollar bills, a blank envelope for themselves that said "keep," a blank envelope for the recipient that said "send," an informational sheet about the recipient, and a short letter explaining the task that generated the payment, aimed at the recipient. The letter provided information about each recipient such as the average income, home ownership rate, and average home price in the recipient's city. We referenced two cities, one relatively 'rich' (median income of $\$ 88,193$ and average home price of $\$ 268,700$ ) and the other relatively 'poor' (median income of $\$ 39,116$ and average home price of $\$ 133,300) .^{13}$

\footnotetext{
${ }^{13}$ Note that we did not explicitly use terms such as rich and poor in the instructions, nor did we tell participants in advance that they would sometimes be matched with a well-off and other times with a less-well-off individual. Rather, the socio-economic information referred to was simply provided as part of the description of the potential recipient each time a decision was to be made.
} 
We told parents either that their decision would be shown to their own child prior to the child making a similar decision (Show condition), or that their decision may be shown to another participating child - but not their own child - prior to that child making a similar decision (No Show condition). ${ }^{14}$ All parents made two Show decisions, one to 'poor' and one to 'rich,' and two No Show decisions, one to 'poor' and one to 'rich.' We varied the order of the decisions, as indicated in Table 1. As we explain later, in our analyses we only use giving to 'poor' data.

All children acted as dictators in three consecutive games, matched with three different anonymous receiver children, each time choosing how to divide six stickers between themselves and the other child. Prior to starting each game, children selected a preferred sticker pack from among six different packs. Since we could not use cash incentives with young children, this was our attempt to make sure that all children received incentives that they liked. Stickers have been used as dictator game currency in previous studies with children (e.g., Li et al., 2013). To make a decision, children were asked to place stickers either on a plate that was for them to keep, or on another plate to send to the other child.

In the child dictator games, we provided information about whether the recipient was relatively 'rich' (had a large house and many toys) or relatively 'poor' (had a small house and few toys). They played the first two games in one of two orders, rich recipient then poor recipient, or poor then rich. These two games were carried out without any influence (No Influence condition). In the third and final game, children always made a decision about giving to a poor recipient. ${ }^{15}$ For this third game we assigned the children randomly into one of two treatments, or to a control group.

\footnotetext{
${ }^{14}$ For the own child, we said 'will be shown.' For the other child, we said 'may be shown' rather than 'will be shown' because not all parents' decisions could be shown to the other child. However, we were clear in the No Show condition that the parent's decisions would not be shown to their own child.

${ }^{15}$ As with the adults, explicit use of terms like rich or poor and prior notification that relative wealth or poverty of recipients would vary across tasks were not given.
} 
In one treatment children were told what their parent has done in a similar game (Influence condition - Parent) before the children made their own decision. In the second treatment children were told what another adult (but not their own parent) did in a similar game (Influence condition - Other Adult). ${ }^{16}$ The decision is described as a similar choice made by the parent or another adult; how much the parent or other adult gave is described in words and also displayed in an animation (which shows giving of dollars rather than of stickers) on the computer screen. Then, children made a dictator game decision with a poor recipient. The third group of children was the control group, who made their decision exactly like in the previous No Influence condition (also with a poor recipient).

In all parent and child games we matched the gender of the recipient to the child dictator's gender. For example, if the child was female, both the child and parent (mother or father) were matched to another female; if the child was male, both the child and parent (mother or father) were matched to another male. Matching gender is a common protocol for child studies, since it reduces noise associated with introducing additional variation in recipient information and suggests that the recipient may like a similar type of sticker set chosen by the dictator (e.g., Blake and Rand, 2010).

In sum, we have data on parent choices both with and without showing to their own children (to measure parent modeling). We also have child choices made before exposure to adult decisions, and ones made after seeing what a parent or another adult has done (to measure emulation). While parents and children make decisions both on sending to poor and less poor recipients, emulation and modeling are studied only for the transfer to poor decisions.

\footnotetext{
16 Thus in the Influence condition - Parent, a child saw his or her parent's decision made in the Show condition. In the Influence condition - Other Adult, the child saw what an adult (another child's parent) did in the No Show condition.
} 


\section{Results and Analysis}

\subsection{Data}

Of the 147 children, 70 were boys and 77 were girls. The mean (and median) age was 4.5 years, with a minimum of 3.2 and a maximum of 6.1 (with only one child in the sample having turned 6 at the time of the experiment). Half of the children were Hispanic, a third black, and the remainder white. Of the 147 parents, 49 were fathers and 98 mothers.

\subsection{Overview of Decisions}

We analyze only data for giving to 'poor' ${ }^{17}$ and the summary statistics for giving by parents and children in the various experimental conditions Tables $2 \mathrm{a}$ and $2 \mathrm{~b}$ pertains only to that giving. There are no statistically significant order effects for adults or children. Hence, in the analyses that are reported below, no dummy for order is included (including one does not affect the results).

The mean giving of $\$ 2.90$ by adults, nearly half of the endowment, is higher than that reported in most other studies (about a third of the endowment—-see Engel, 2011), but this may be due to the fact that the recipient was 'poor.' Giving to 'rich' (not reported in Table 2a) was just over a third of the endowment. The mean giving in both Show and No Show conditions is about $\$ 2.90$, with fathers giving slightly more and mothers slightly less in the Show condition as compared to the No Show condition (statistically insignificant differences). $35 \%$ of parents gave less than half of their endowment, $47 \%$ gave exactly half of their endowment, and $18 \%$ gave more than half; the distributions are similar between mothers and fathers.

\footnotetext{
${ }^{17}$ We chose to have only three rounds for children rather than four like for parents because of children's limited attention span. We chose not to have a condition in which the child is shown giving to "rich."
} 
For children, the mean giving is about 1.90 stickers on average out of each 6 sticker endowment, as compared to parents' $\$ 2.90$ out of $\$ 6$ (and children give the same amount to 'poor' as to 'rich' recipients). Child giving in our experiment is comparable to that in other dictator games with preschoolers: for example, in List and Samek (2013) children give about $25 \%$ of their marshmallow endowment to an anonymous recipient, while children in our experiment give away about $30 \%$ of their endowment. In the No Influence condition, $55 \%$ of children give less than half of their endowment, $34 \%$ give exactly half, and $11 \%$ give more than half. A slightly higher percentage of girls than boys gives less than half of the endowment (57\% versus $53 \%$ ), and a slightly higher percentage of girls than boys give exactly half of the endowment (38\% versus $30 \%)$. Whereas $17 \%$ of boys give more than half, only $5 \%$ of girls do so. We use these ranges in the analysis below to classify child "type." Like in related studies, older children in our study give more than younger children (mean giving in the No Influence condition for below median-aged children is 1.73 stickers and at or above median is 2.13).

Figure 1 presents the distributions of child and adult giving in the various experimental conditions. The distributions show several patterns. First, the two panels describing child giving, without influence and with influence of parent and other adult giving (thus excluding the 28 children in treatment "repeat of No Influence" in round three), are quite similar. Second, adults' giving shows much similarity between the two conditions. Third, the children's and adults' distributions look different. Preschoolers give a lower proportion of their endowment overall and their giving is bimodal, with similar fractions splitting the stickers equally and giving no stickers, whereas parental giving shows a clear mode at an equal split of dollars. Finally, while each group's decisions are similar with and without the possibility of influence, there are signs that parental choices may influence those of children. 
To gain more insight into how stable or sensitive to Show versus No Show and Influence versus No Influence conditions parents' and children's behaviors are, we examine Tables $3 \mathrm{a}$ and 3b. The tables summarize the transition between decisions in the No Show condition to those in the Show condition, for parents, and from the No Influence to the Influence condition, for children. In these tables and in some of our analyses, we group giving decisions (from among the seven available options $(0,1, \ldots 6))$ into three broad bins. Specifically, we call a child or adult who gives 0,1 or 2 in the No Influence or No Show condition "selfish," one who gives 3 (exactly half) "fair," and one who gives 4, 5, or 6 "generous." The reader should understand these three terms as if quotation marks apply in every usage, since we are by no means asserting that we have measured the true character of each participant in our simple setting. We use 3 for the "fair" category not as an ethical judgment but due to its focal point status, which is evident from Figure 1.

The relative stability of types is manifest along the Table 3 diagonals for both parents and children. Yet some movement is also noticeable for both. Thus 10 of 41 selfish parents in No Show chose to be fair or generous in the Show condition, and 14 of 68 children made a similar transition from No Influence to Influence. Whereas the great majority of generous parents remained such in the Show condition, 9 of the 16 children who were generous in the No Influence condition became selfish and 3 became fair in the Influence condition. Most Fair parents remained Fair in the Show condition, with 12 out of 48 changing to selfish and 9 to generous, and most fair children remained fair, with 10 out of 38 changing to selfish in Influence, with another 6 changing to generous. These are interesting dynamics that reveal substantial heterogeneity in both types and in changes in types. We analyze the data underlying Table 3 in the context of the teaching and emulation effects in Sections 5.4 and 5.5. But first we turn to examine the first question, whether there is similarity between parent and child giving. 


\subsection{Test of the Family Hypothesis}

To evaluate the family/inheritance effect we investigate the relationship between what the 147 children and their parents send in experiments when they play dictator games in the No Show and No Influence conditions, $Y_{N I}$ and $X_{N S}$, respectively. To test for possible differences associated with age and gender, we also control for these factors. We further test differences associated with age by splitting the sample at the median age ( 4.5 years) and conducting similar analyses on the subsamples of younger and older preschoolers.

Begin by noting that child and adult giving are restricted to integers (whole stickers or dollars). Some children (adults) may have wanted to give fractions of stickers (dollars), others may have wanted to give less than 0 - that is, to get stickers (dollars) from the other child (adult) or give more than the six stickers (dollars) endowment. To account for the nature of the data and their distribution, we use ordered probit, with $y^{*}$ a conventional latent variable for child integer giving in the No Influence condition. ${ }^{18}$ Equation (16), where child indexing has been suppressed, represents our first analysis,

$$
y^{*}=\sum_{k=1}^{K} \beta_{k} D_{k}+\left(\alpha+\sum_{k=1}^{K} \beta_{k} D_{k}\right) X_{N S}+\varepsilon
$$

The notation is defined in the lower panel of Table $1 . D_{k}$ consists of father and mother dummies (the latter is the reference category), boy and girl (the latter is the reference category), pairing of father-son, father-daughter, mother-son and mother-daughter (the latter is the reference category), age groupings of 3, 4 and 5 year olds (4 year old is the reference category), and black, Hispanic and white (the latter is the reference category). Using continuous age in weeks does not alter the estimates on non-age variables. Evidence for transmission through genetic inheritance

\footnotetext{
${ }^{18}$ We used Stata v. 11 oprobit command, which employs a MLE. No constant is estimated; the thresholds, cut1, cut2, etc. (with reversed signs) are the intercepts.
} 
and/or family environment would be represented by a non-zero estimate of $\alpha$. We include a number of different estimations to explore possible effects of parent and child gender.

The results of these estimations are presented in Table 4a. There is no significant correlation between $Y_{N I}$ and $X_{N S}$, giving by children and their parents when there is no consideration of modeling for the parent and the variation in $Y_{N I}$ explained by this analysis is essentially nil. There is no inheritance effect moderated by parent gender (column 2) or child gender (column 3). There is no inheritance effect when we consider parent-child gender pairing (column 4), child age (column 5) and race/ethnicity (column 6), the latter two very mildly moderating the relationship between parent and child giving (as indicated by marginally significant coefficients on the relevant interaction terms). We obtain similar results when we split the sample by mean age (which coincides with median age) of 4.5 years. (Results based on the two subsamples for this and subsequent analyses are available upon request). The broad conclusion we draw from this analysis is that there is no meaningful association between the giving of parents and their preschool-age children in our dictator games.

It is conceivable that parents model behaviors consistently over time that reflect preferences they would like their children to have, as we predicted in Hypothesis 3, and that this intentional modeling differs from their behaviors when unwatched. If so, $Y_{N I}$ could be correlated with $X_{S}$ rather than $X_{N S}$. We repeated the analysis reported in Table 4a with $X_{S}$, but again found no correlations.

We also consider whether there is intergenerational transmission of giving inclination as represented by our three "type" categories — selfish, fair, and generous. In Table $4 \mathrm{~b}$ we present a multinomial logit analysis of determinants of child type by parent type, with controls (interaction terms are not presented for space reasons, but including interactions does not change the results). 
Results for subsamples of older and younger children are similar to those based on the full sample. In conclusion, we do not find support for Hypothesis 1, that parent and child giving should be correlated due to the family inheritance effect.

We speculate that there may be several reasons for this result. First, we see suggestive evidence that older children (those aged 5-6) are more likely to behave like their parents, so perhaps because moral development is still ongoing at this early age, the child has not yet fully expressed the behavior of his or her parents. Second, it is possible that the influence of the family is not as strong as we may have expected a priori. In fact, several other studies also find no correlation between sharing behavior of parents and children even when children are a little older (Bettinger and Slonim, 2005; Cipriani et al., 2013). Finally, there could be other environmental influences that we have not controlled for, such as a random element influencing how the tasks are construed by each participant.

\subsection{Test of the Emulation Hypothesis}

While children do not seem to take on the preferences of their parents at the young age of $3-5$, perhaps they are influenced by their parents' choices when they see these choices prior to making their decision. This is the basis of Hypothesis 2, which proposes that children emulate their parents, that is, that $Y_{I}$ is influenced by $X_{S}$. Emulation is assessed in equation (17), which relates what a child gives in the No Influence and Influence conditions ( $Y_{N I}$ and $Y_{I}$, respectively) to what the adult gives in the Show condition $\left(X_{S}\right)$ multiplied by the Show-No Show dummy R ( 0 and 1, respectively), and child fixed effects. The influence of $X_{S}$ on child giving in the two conditions may be affected (moderated) by child's ethnicity/race, age, whether he or she was exposed to the mother or father's decision, or that of another adult, and the child's own type. We evaluate the role 
of these variables in the ordered probit model in equation (17) below, where $y^{*}$ is a latent variable for $Y_{N I}$ and $Y_{I}, D_{k}$ variables are child demographics and source of influence, and $d_{i}$ s are child dummies:

$$
y^{*}=\left(\alpha X s+\sum_{k=1}^{K} \beta_{k} D_{k} X s\right) R+\sum_{i} \gamma_{i} d_{i}+\varepsilon
$$

The results are presented in Table 5. The number of observations is 234 , with two observations for each of the 117 child-parent pairs, after excluding the children that were in the control group of No Influence condition in round three. ${ }^{19}$ We consider parent influence separately for father and mother, with other adult influence as the omitted category. To conserve space, we did not include in Table 5 age and ethnicity variables, the estimates on which are very small and statistically insignificant.

The story told by Table 5 is interesting. The principal explanatory variable is $\left(X_{S}\right) * \mathrm{R}$, adult Show condition sending interacted with $\mathrm{R}$, a dummy variable distinguishing child Influence condition $(\mathrm{R}=1)$ from the Uninfluenced condition $(\mathrm{R}=0)$. In the first specification, the estimated coefficient on this variable is negative and insignificant, providing no support for the hypothesis of adult influence. Column (2) adds separate interactions for father and mother, distinguished from other adult, but all variables remain insignificant.

This changes dramatically in specification (3), which adds to the column (1) specification an interaction between $X_{s}^{*} R$ and the child's Uninfluenced sending $Y_{N I}$. With this addition, the coefficient on $X_{s}^{*} R$ becomes large, positive, and significant, in line with Hypothesis 2, while the coefficient on the interaction term is an equally significant negative term of somewhat over a third

\footnotetext{
${ }^{19}$ Recall that in the third (and last) round children were divided into three treatment groups: in one group children were shown their own parents' giving, in another group they were shown the giving of an adult who is not their parent (this adult was a parent of another child), and a third group repeated the No Influence condition. For clarity, in Table 5 we use only the parent and other adult data, omitting the children under No Influence in this round. However, the inclusion of that group as a separate category does not qualitatively affect the results.
} 
the first coefficient's magnitude. We interpret this to mean that a child who sent nothing in the Uninfluenced condition comes close to copying the adult's choice, but that the greater was $Y_{N I}$, the less fully is the adult copied, which may partly be a mechanical consequence of there being less (or no) room for a child near (or at) the maximum sending level to increase sending in response to the observed adult behavior. Column (6) adds father and mother interactions like those in column (2) to the column (3) specification. The two significant terms in column (3) remain significant and little changed in value, while the coefficients on the added interaction terms are entirely insignificant. This is interesting since it suggests that the emulation indicated by the first coefficients in specifications (3) and higher might reflect emulation of any adult (or conceivably even copying of any illustrative decision shown to the child), not the specific influence of parents. ${ }^{20}$

In columns (4), (5) and (7), we explore the possibility that boys and girls respond differently to adult influence. Column (4) adds only an interaction with a gender dummy (boy = 1) to specification (1). The result shows that adding this interaction alone is sufficient to change the insignificant negative coefficient on $X_{s}^{*} R$ in (1) to one that is positive and significant. The interaction of $X_{s}^{*} R$ with Boy is negative, significant, and of larger absolute value, seemingly suggesting that while girls somewhat emulate the adults, boys adjust in the opposite direction. However, the specifications in columns (5) and (7) suggest that once the moderating effect of the child's Uninfluenced decision is taken into account, any gender difference in emulation tendencies becomes insignificant. The other qualitative effects shown in column (3) remain the same in specifications (5), (6) and (7).

\footnotetext{
${ }^{20}$ When assessing the lack of differentiation of reactions to parental and other role models, it is important to keep in mind the children's ages and the fact that the adult decisions were illustrated for them by a simple video of cartoonlike hands moving dollars. Neither other adult nor parent were physically, or even visually, present when the information was being conveyed. Appendix II contains the exact text of the child instructions.
} 
In sum, these regressions show that preschoolers were significantly influenced by the adult giving decisions shown them, although the impact is smaller in magnitude the larger the child's Uninfluenced sending decision. The preschoolers did not respond differently when told that the adult in question was their father, mother, or another adult, and once the moderating effect of Uninfluenced sending is controlled for, emulation by boys is not different from that of girls.

\subsection{Test of Role Modeling Hypothesis}

Finally, we test the role modeling effect predicted by Hypothesis 3 . To test this hypothesis, we compare the decisions made by parents in the Show and No Show conditions. As previously discussed, parental decisions about modeling behavior to their child could differ depending on what they assess the particular child's disposition to be-i.e., the parent might urge fairness concerns on a child she perceives as being overly selfish, but might take a different approach towards a child who seems to show too little self-concern. We allow for this in our analysis by using our child types as above, based on each preschooler's uninfluenced giving $Y_{N I}$ and assuming that the parent has knowledge of the child's disposition (the parent is not told explicitly about the child's uninfluenced giving). The modeling effect is then estimated by including child type, as well as adult fixed effect and parent-child gender pairing. Since adult giving bears the same restrictions as child giving, we use ordered probit and a latent variable $x^{*}$ for $X_{S}$ and $X_{N S}$; see equation (18).

$$
x^{*}=\left(\alpha+\sum_{k=1}^{K} \beta_{k} D_{k}\right) D_{\text {show }}+\sum_{i} \gamma_{i} d_{i}+\varepsilon
$$

There are 292 observations in Table 6, where the results are presented, coming from all 147 parents in the No Show and Show conditions. Table 6 reflects decisions of parents who know, in the Show condition, that their own child will see the decision, whereas in the No Show condition 
the parents were told that their own child would not see their decision (but another child may). In the first specification, the estimate on the Show (vs. No Show) dummy alone is small and statistically insignificant. However, there is a possibility of heterogeneity in parental behavior; the remaining specifications explore this possibility. In column (2) we consider whether the parent is the father or mother. In this specification, the coefficient on $D_{\text {show }}$ is negative and marginally significant, but its interaction with the father dummy is positive, almost three times as large, and is significant at the $5 \%$ level, indicating that fathers substantially increase their giving when it will be shown to their child, whereas mothers if anything slightly reduce theirs, in the Show as compared to the No Show condition (the estimated coefficient is quite large relative to the differences in cut points). When we estimate model (1) separately for fathers and mothers, the estimate on $D_{\text {show }}$ for fathers is 0.563 (estimated SE 0.321 , significant at $10 \%$ ) and for mothers it is -0.413 (estimated SE 0.222 , significant at $10 \%$ ). There appear to be no child gender, ethnicity/race or age effects in parent's decisions (columns 3, 4 and 6).

In column (5), we control for interaction with child type and find that parents of generous children (in their giving in the No Influence condition) increase their own giving between No Show and Show conditions significantly more than other parents do. No effect is detected for parents of Selfish children.

In sum, Table 6 provides evidence of parents modeling to their preschoolers. There is a significant tendency in our sample for fathers to show more generosity when they know their decision will be made known to their child, while there is marginally significant evidence of a smaller shift in the opposite direction by mothers. ${ }^{21}$ There is also evidence that parents of more

\footnotetext{
${ }^{21}$ Note that Table 2a does not support an explanation that fathers behave significantly more selfishly when unobserved and that their shift upwards in sending in the Show condition is attributable to some need to more closely conform with the altruism of mothers when being watched.
} 
generous children give more when their child will see their decision. Greater sending in general, and greater sending in particular to a more generous child, were predicted in Hypothesis 3 owing to two factors: (i) that parents attempt to transmit their behavioral ideals to their children and that when parents' ideals of giving differ from their unwatched behaviors, their ideals tend to be more generous than their unwatched behaviors, and (ii) that parents take into account the child's disutility from a gap between parent and child behavior and therefore altruistically attempt to reduce the size of that gap. Factor (ii) predicts greater sending when watched by a generous child provided that parents can make better-than-random guesses about their child's uninfluenced generosity (not shown to them in the experiment). We did not predict greater paternal than maternal modeling, and indeed our general prediction of modeling failed to be supported in the data with respect to mothers.

\section{Conclusion}

The question of whether, and how, parents transmit normative preferences or values to children is an interesting and potentially important one that has barely begun to be studied empirically by economists, despite its relevance to the economics of the family, philanthropy, civic cooperation, and other domains. We propose a theoretical model that predicts parental role modeling to children, and children's emulation of parents' decisions, as a possible mechanism for transmission. We test our theory through an experiment in which we asked preschoolers and their parents to participate in dictator games allocating items - stickers for the children, dollars for the adults - between themselves and an unknown other child or adult. One of a parent's decisions was shown either to their own child or to an unrelated child. Our analysis focused on (1) whether children's and parents' decisions when the parent is not concerned about their own child seeing it and before the child has seen his or her parent's decision, are correlated (inheritance effect), (2) 
whether parents make different choices when they know a choice may be shown to their own child (modeling effect), and (3) whether children's choices change to resemble those of their parent or another adult after such a choice is shown to them (emulation effect).

Our main results include: (1) we do not find a family inheritance effect (i.e., there is no correlation between parental decisions in the No Show condition and child decisions in the No Influence condition, in our data); (2) we find evidence of parental modeling (i.e., parents increase their giving when it is to be shown to their own child - the Show condition) in the case of fathers but not mothers and in that of parents of children who gave generously, but not others; and (3) we find an emulation effect insofar as children who divide stickers unequally - whether giving more or less than an equal split - in the Uninfluenced condition, tend to shift giving after seeing the choice of their parent or another adult, narrowing if not fully eliminating the difference.

Our sample size is modest and our results may accordingly be sensitive to idiosyncratic aspects of the sample, as well as to the details of our procedure. Our study may therefore be at least as important for the questions it poses, the analytical approach it proposes, and as an initial trial of a design geared to study these questions, as for the exact findings, which will require future replication and testing for robustness. Treating these findings as worthy of initial interpretation, we argued that the very young age of the pre-school subjects might be the main cause of a null result on inheritance. The tendency of parents to increase their giving behavior when observed by children already displaying a tendency towards generosity may reflect the fact that these children have already been influenced by similar parental modeling at home, as well as by the desires of the parents not to create disutility-fostering dissonance by deviating from the inclination of their tender-hearted preschooler. We could provide no explanation of paternal but not maternal 
modeling. ${ }^{22}$ The fact the child emulation effect was observed among children who had not chosen an even split before observing the adult influence, but not among those who had, may reflect, among other things, the stickiness of the equal split focal point.

Finally, when evaluating the lack of difference in child response to other adult versus parent, it is important to bear in mind that in our design, the child did not observe the parent or adult acting, but rather was shown a depiction of the action by an experimenter, with only the experimenter's verbal description of who had made that decision differing between parent and other adult cases. For very young children, the difference in influence could be sensitive to whether the relevant adult or parent is seated close by, viewed through a window or video monitor, or merely verbally described. Thus, our main conclusion is that we have evidence of child emulation, as proposed in our model, but inferences about the relative importance of parental role modeling, if any, should be drawn with caution.

\footnotetext{
${ }^{22} \mathrm{We}$ reiterate that the conjecture that only fathers seem to raise their giving because they are less generous than
} mothers when not observed is not supported by our data. 


\section{References}

Bar-Tal, D., Raviv, A., \& Leiser, T. (1980). The development of altruistic behavior: Empirical evidence. Developmental Psychology, 16(5), 516.

Bauer, Michal, Chytilová, J., \& Pertold-Gebicka, B. (2014) "Parental background and other-regarding preferences in children." Experimental Economics 17(1), 24-46.

Becker, Gary S. (1974). "A Theory of Social Interactions." Journal of Political Economy 82(6), 1063 93.

Becker, Gary S., Murphy, K., \& Spenkuch, J. (2014). "The Manipulation of Children's Preferences, Old Age Support, and Investment in Children's Human Capital". Working Paper

Benenson, Joyce F., Pascoe, J., \& Radmore, N. (2007) "Children's altruistic behavior in the dictator game." Evolution and Human Behavior 28(3), 168-175.

Bettinger, Eric, \& Slonim, R. (2005). Using Experimental Economics to Measure the Effects of a Natural Educational Experiment on Altruism. No. w11725. National Bureau of Economic Research.

Blake, Peter, Corbit, J., Callaghan, T., \& Warneken, F. (2014). "Give as I Give: Socialization Goals in Two Cultures Moderate Parental Influence on Children's Giving," unpublished paper, Boston University.

Blake, P. R., \& Rand, D. (2010). "Currency value moderates equity preference among young children." Evolution and human behavior 31(3), 210-218.

Bloom, P. (2013). Just Babies: The Origins of Good and Evil. Crown Publishing.

Boyd, R., \& Richerson, P. (2005). Not by Genes Alone: How Culture Transformed Human Evolution. Chicago: University of Chicago Press.

Cesarini, D., Dawes, C. T., Fowler, J. H., Johannesson, M., Lichtenstein, P., \& Wallace, B. (2008). "Heritability of cooperative behavior in the trust game," Proceedings of the National Academy of sciences, 105(10), 3721-3726.

Cipriani, M., Giuliano, P., \& Jeanne, O. (2013). "Like mother like son? Experimental evidence on the transmission of values from parents to children." Journal of Economic Behavior \& Organization 90, 100-111.

Devanath, S. (2010). "How Socialization Relates to Early Prosocial Development," Bachelor's Thesis, University of Pittsburgh Departments of Sociology and Psychology.

DeWaal, Frans. (2009). The Age of Empathy: Nature's Lessons for a Kinder Society. Crown Publishing. 
Engel, Christoph. (2011). "Dictator games: a meta study." Experimental Economics 14(4), 583-610.

Fehr, E., \& Rockenbach, B. (2004). Human altruism: economic, neural, and evolutionary perspectives. Current opinion in neurobiology, 14(6), 784-790.

Fehr, E., Bernhard, H., \& Rockenbach, B. (2008). "Egalitarianism in Young Children," Nature, 454(7208), 1079-1083.

Fehr, E., Rützler, D., \& Sutter, M., (2011). “The Development of Egalitarianism, Altruism, Spite and Parochialism in Childhood and Adolescence," Working Paper.

Gummerum, M., Hanoch, Y., Keller, M., Parsons, K., \& Hummel, A. (2010). “Preschoolers’ Allocations in the Dictator Game: The Role of Moral Emotions," Journal of Economic Psychology 31(1), 25 -34 .

Harbaugh, W. T., \& Krause, K. (2000). "Children's altruism in public good and dictator experiments." Economic Inquiry 38(1), 95-109.

Harbaugh, W. T., Krause, K., \& Liday, S. J. (2003). "Bargaining by children." University of Oregon Economics Working Paper 2002-4.

Harris, P. (2012). Trusting What You're Told: How Children Learn From Others. Belknap Press of Harvard University Press.

Harrison, G.W. and List, J.A. (2004). "Field Experiments.” Journal of Economic Literature 42(4), 10091055

Hoffman, M. L. (1975). “Altruistic Behavior and the Parent-Child Relationship,” Journal of Personality and Social Psychology 31(5), 937.

Houser, D., Montinari, N., \& Piovesan, M., (2012) "Private and Public Decisions in Social Dilemmas: Evidence from Children's Behavior," PLoS ONE 7(8) e41568, 1 - 6.

Kosfeld, M., Heinrichs, M., Zak, P.J., Fischbacher, U., \& Fehr, E. (2005). "Oxytocin increases trust in humans." Nature 435(7042), 673-676.

Li, Y., et al. (2013). "Experiencing a natural disaster alters children’s altruistic giving." Psychological Science 24(9), 1686-1695.

List, J. (2007). “On the Interpretation of Giving in Dictator Games,” Journal of Political Economy 115(3), $482-493$.

List, J. \& Samek, A. (2013). "Exploring the Origins of Charitable Acts: Evidence from an Artefactual Field Experiment with Young Children," Economics Letters 118(3), 431 - 434. 
Ottoni-Wilhelm, M., \& Ye Zhang. (2011) "What Motives Cause Parents to Transmit Generosity," Working Paper, IUPUI.

Rushton, J. P. (1975). “Generosity in Children: Immediate and Long-term Effects of Modeling, Preaching, and Moral Judgment," Journal of Personality and Social Psychology 31(3), 459.

Smith, A. (1759). The Theory of the Moral Sentiments.

Wallace, B., Cesarini, D., Lichtenstein, P., \& Johannesson, M. (2007). Heritability of ultimatum game responder behavior. Proceedings of the National Academy of Sciences, 104(40), 15631-15634.

Warneken, F. (2013). “Young Children Proactively Remedy Unnoticed Accidents,” Cognition 126, 101 108.

Warneken, F., \& Tomasello, M. (2009). “The Roots of Human Altruism,” British Journal of Psychology $100(3), 445-471$.

Warneken, F., \& Tomasello, M. (2013). "Parental Presence and Encouragement Do Not Influence Helping in Young Children," Infancy 18(3), 345 - 368.

Wilhelm, Mark Ottoni, Eleanor Brown, Patrick M. Rooney, and Richard Steinberg. "The Intergenerational Transmission of Generosity." Journal of Public Economics 92, no. 10-11 (2008): 2146-156.

Zinser, O., Perry, J., \& Edgar, R. (1975). "Affluence of the Recipient, Value of Donations, and Sharing Behavior in Preschool Children,” Journal of Psychology 89, 301 - 305.

Zumbühl, M., Dohmen, T., \& Pfann, G. (2013). "Parental Investment and the Intergenerational Transmission of Economic Preferences and Attitudes," IZA Working Paper 7476. 
Table 1. Summary of Experimental Design and Notation (see Appendix for details)

\begin{tabular}{|c|c|c|}
\hline & Parents & Children \\
\hline Endowment & $\$ 6$ & 6 preferred stickers \\
\hline Receiver 'Poor' $\mathbf{P}$ & $\begin{array}{l}\text { P: "Lives in a neighborhood where yearly } \\
\text { incomes vary around the mid-point of } \\
\mathbf{\$ 3 9 , 1 1 6} \text {. This income means that there is } \\
\text { about } \$ \mathbf{1 5 , 9 2 4} \text { for each person in a family. } \\
\text { Lives in a neighborhood where } \mathbf{6 5 \%} \text { of } \\
\text { people own their home and the average } \\
\text { cost of a home is } \mathbf{\$ 1 3 3 , 3 0 0 . "}\end{array}$ & $\begin{array}{l}\text { P: "has few toys to play with at home" - small house } \\
\text { pictured. }\end{array}$ \\
\hline Receiver 'Rich' R & $\begin{array}{l}\text { R: "Lives in a neighborhood where yearly } \\
\text { incomes vary around the mid-point of } \\
\mathbf{\$ 8 8 , 1 9 3} \text {. This income means that there is } \\
\text { about } \$ \mathbf{4 8 , 1 0 5} \text { for each person in a family. } \\
\text { Lives in a neighborhood where } \mathbf{9 6 \%} \text { of } \\
\text { people own their home and the average } \\
\text { cost of a home is } \mathbf{\$ 2 6 8 , 7 0 0 . "}\end{array}$ & $\begin{array}{l}\text { R: "has a lot of toys to play with at home" - large house } \\
\text { pictured }\end{array}$ \\
\hline $\begin{array}{l}\text { Experimental } \\
\text { conditions } \\
\text { and sample } \\
\text { instructions. } \\
\text { In the NS and NI } \\
\text { conditions there was } \\
\text { same-gender pairing }\end{array}$ & $\begin{array}{l}\text { NS: No Show: "In this round, some } \\
\text { children from today's activity may be } \\
\text { shown the choices that you made before } \\
\text { they make their choices in the child activity } \\
\text { right after this. However, your own child } \\
\text { will not see the choices you made for this } \\
\text { round..." } \\
\text { S: Show: "In this round we will show your } \\
\text { child the choices you made before he/she } \\
\text { makes some of his/her choices in the child } \\
\text { activity that's just getting started" }\end{array}$ & $\begin{array}{l}\text { NI: No Influence: "On this plate there are some stickers. } \\
\text { They are yours now. You are going to decide how many to } \\
\text { keep, and how many to send to this [boy, girl]. You can keep } \\
\text { as many of your stickers as you want, and you can send } \\
\text { none, some, or all of your stickers to [him, her]. It is up to } \\
\text { you how many you keep and how many you send..." } \\
\text { I: Influence: "...But before you make your own choice, I } \\
\text { want to tell you that other people played a similar game } \\
\text { before you. They did not play the game with [boy, girl] but } \\
\text { with similar people. Here is what [your mother, your father, } \\
\text { another adult] did (animation)..." }\end{array}$ \\
\hline $\begin{array}{l}\text { Experimental rounds } \\
\text { by receiver and } \\
\text { condition }\end{array}$ & $\begin{array}{l}\text { a. NS-R, NS-P, S-R, S-P } \\
\text { b. S-R, S-P, NS-R, NS-P } \\
\text { (no statistically significant order effects) }\end{array}$ & $\begin{array}{l}\text { a. NI-P, NI-R, I-P (Mother, Father or Other Adult) } \\
\text { b. NI-R, NI-P, I-P (Mother, Father or Other Adult) } \\
\text { c. NI-R, NI-P, NI-P } \\
\text { (no statistically significant order effects) }\end{array}$ \\
\hline
\end{tabular}

\begin{tabular}{|c|c|}
\hline $\begin{array}{l}\mathbf{X}_{\mathbf{n s}} \text { : Adult giving in the No Show condition } \\
\mathbf{X}_{\mathbf{s}} \text { : Adult giving in the Show condition } \\
\mathbf{Y}_{\mathbf{n i}} \text { : Child giving in the No Influence condition } \\
\mathbf{Y}_{\mathbf{i}}: \text { Child giving in the Influence conditions } \\
\mathbf{x}^{*}=\text { latent variable for Xns and Xs } \\
\mathbf{y}^{*}=\text { latent variable for Yni and Yi } \\
\mathbf{D}_{\text {show }}=1 \text { for Show condition, }=0 \text { for No Show } \\
\mathbf{R}=\text { round } 3 \text { of child experiment }=1 \text { for Influence } \\
\text { condition, }=0 \text { for No Influence }\end{array}$ & $\begin{array}{l}\text { Child/adult type } \\
\qquad \begin{array}{l}\cdot \quad \text { Selfish: } Y_{N I} / X_{n s}=0,1 \text { or } 2 \\
\cdot \quad \text { Fair: } Y_{N I} / X_{n s}=3\end{array} \\
\text { Generous: } Y_{N I} / X_{n s}=4,5 \text { or } 6 \\
\mathbf{D}_{\mathbf{k}}=\text { vector of dummies for child type, gender, age and } \\
\text { ethnicity } \\
\mathbf{d}_{\mathbf{i}}=\text { individual dummy variables (child or adult, } \\
\text { depends on the context) }\end{array}$ \\
\hline
\end{tabular}


Table 2a. Summary Statistics for Adults' Giving

\begin{tabular}{|c|c|c|c|c|c|}
\hline Giving & Sample size & Mean & Standard error & Minimum & Maximum \\
\hline Parent-no show ( $\left.\mathrm{X}_{\mathrm{NS}}\right)$ & 147 & 2.91 & 1.48 & 0 & 6 \\
\hline Parent-show $\left(\mathrm{X}_{\mathrm{s}}\right)$ & 146 & 2.90 & 1.61 & 0 & 6 \\
\hline Father-no show & 49 & 2.86 & 1.67 & 0 & 6 \\
\hline Father-show & 48 & 3.04 & 1.75 & 0 & 6 \\
\hline Mother-no show & 98 & 2.94 & 1.39 & 0 & 6 \\
\hline Mother-show & 98 & 2.83 & 1.54 & 0 & 6 \\
\hline \multicolumn{6}{|c|}{ Parent type classification by number of dollars given in the No Show condition } \\
\hline \multicolumn{2}{|c|}{$\begin{array}{l}\text { Selfish (gave less than half): } 51 \text { (18 } \\
\text { fathers, } 33 \text { mothers) }\end{array}$} & \multicolumn{2}{|c|}{$\begin{array}{l}\text { Fair (gave half): } 69 \text { ( } 22 \text { fathers, } 47 \\
\text { mothers) }\end{array}$} & \multicolumn{2}{|c|}{$\begin{array}{l}\text { Generous (gave more than half): } 27 \text { (9 } \\
\text { fathers, } 18 \text { mothers) }\end{array}$} \\
\hline
\end{tabular}

Table 2b. Summary Statistics for Children's Giving

\begin{tabular}{|c|c|c|c|c|c|}
\hline Giving $\left(Y_{i}\right)$ & Sample size & Mean & Standard error & Minimum & Maximum \\
\hline No influence & 147 & 1.91 & 1.64 & 0 & 6 \\
\hline Boy & 70 & 2.11 & 1.79 & 0 & 6 \\
\hline Girl & 77 & 1.73 & 1.47 & 0 & 6 \\
\hline Third round & 145 & 1.89 & 1.66 & 0 & 6 \\
\hline $\begin{array}{l}\text { Father } \\
\text { influence }\end{array}$ & 40 & 1.93 & 1.67 & 0 & 6 \\
\hline $\begin{array}{l}\text { Mother } \\
\text { influence }\end{array}$ & 37 & 2.05 & 1.81 & 0 & 6 \\
\hline $\begin{array}{l}\text { Other adult } \\
\text { influence }\end{array}$ & 40 & 1.75 & 1.63 & 0 & 6 \\
\hline $\begin{array}{l}\text { Repeat of } \\
\text { No } \\
\text { influence }\end{array}$ & 28 & 2.04 & 1.55 & 0 & 6 \\
\hline \multicolumn{6}{|c|}{ Child type classification by number of stickers given in the No Influence condition } \\
\hline \multicolumn{2}{|c|}{$\begin{array}{l}\text { Selfish (gave less than half): } 80 \\
\text { ( } 37 \text { boys, } 43 \text { girls) }\end{array}$} & \multicolumn{2}{|c|}{$\begin{array}{l}\text { Fair (gave half): } 50 \text { ( } 21 \text { boys, } 29 \\
\text { girls) }\end{array}$} & \multicolumn{2}{|c|}{$\begin{array}{l}\text { Generous (gave more than half): } 16 \text { ( } 12 \text { boys, } \\
4 \text { girls) }\end{array}$} \\
\hline
\end{tabular}


Table 3a. Transition table for parents, by type

\begin{tabular}{|l|l|l|l|l|}
\hline & Selfish in Show & Fair in Show & Generous in Show & Total \\
\hline Selfish in No-Show & 41 & 7 & 3 & 51 \\
\hline Fair in No-Show & 12 & 48 & 9 & 69 \\
\hline Generous in No-Show & 1 & 4 & 22 & 27 \\
\hline Total & 54 & 59 & 34 & 147 \\
\hline
\end{tabular}

Table 3b. Transition table for children, by type (excludes children who were in the No Influence condition in the third round)

\begin{tabular}{|l|l|l|l|l|}
\hline & Selfish in Influence & Fair in Influence & Generous in Influence & Total \\
\hline Selfish in No-Influence & 54 & 12 & 2 & 68 \\
\hline Fair in No- Influence & 10 & 22 & 6 & 38 \\
\hline Generous in No- Influence & 9 & 3 & 4 & 16 \\
\hline Total & 73 & 37 & 12 & 122 \\
\hline
\end{tabular}


Table 4a. Family/Inheritance Effect: Ordered Probit

\begin{tabular}{|c|c|c|c|c|c|c|}
\hline & (1) & (2) & (3) & (4) & (5) & (6) \\
\hline Xns & $\begin{array}{l}-0.008 \\
(0.060)\end{array}$ & $\begin{array}{c}0.028 \\
(0.077)\end{array}$ & $\begin{array}{l}-0.044 \\
(0.083)\end{array}$ & $\begin{array}{l}-0.080 \\
(0.111)\end{array}$ & $\begin{array}{l}-0.101 \\
(0.086)\end{array}$ & $\begin{array}{l}-0.388 \\
(0.240)\end{array}$ \\
\hline Father*Xns & & $\begin{array}{l}-0.092 \\
(0.122)\end{array}$ & & & & \\
\hline Father & & $\begin{array}{c}0.234 \\
(0.399)\end{array}$ & & & & \\
\hline Boy*Xns & & & $\begin{array}{c}0.091 \\
(0.120)\end{array}$ & & & \\
\hline Boy & & & $\begin{array}{l}-0.004 \\
(0.392)\end{array}$ & & & \\
\hline (Father-son)*Xns & & & & $\begin{array}{c}0.030 \\
(0.189)\end{array}$ & & \\
\hline (Father- & & & & & & \\
\hline Daughter)*Xns & & & & $\begin{array}{c}0.121 \\
(0.171)\end{array}$ & & \\
\hline (Mother-son)*Xns & & & & $\begin{array}{c}0.214 \\
(0.156)\end{array}$ & & \\
\hline Father-Son & & & & $\begin{array}{c}0.243 \\
(0.551)\end{array}$ & & \\
\hline Father-daughter & & & & $\begin{array}{l}-0.746 \\
(0.605)\end{array}$ & & \\
\hline Mother-Son & & & & $\begin{array}{l}-0.605 \\
(0.509)\end{array}$ & & \\
\hline$(3 \mathrm{YO}) * \mathrm{Xns}$ & & & & & $\begin{array}{c}0.105 \\
(0.147)\end{array}$ & \\
\hline$(5 \mathrm{YO}) * \mathrm{Xns}$ & & & & & $\begin{array}{l}0.266^{*} \\
(0.147)\end{array}$ & \\
\hline $3 \mathrm{YO}$ & & & & & $\begin{array}{l}-0.257 \\
(0.481)\end{array}$ & \\
\hline $5 \mathrm{YO}$ & & & & & $\begin{array}{l}-0.616 \\
(0.473)\end{array}$ & \\
\hline Black*Xns & & & & & & $\begin{array}{c}0.386 \\
(0.256)\end{array}$ \\
\hline Hispanic*Xns & & & & & & $\begin{array}{l}0.429^{*} \\
(0.256)\end{array}$ \\
\hline Black & & & & & & $\begin{array}{l}-0.947 \\
(0.716)\end{array}$ \\
\hline Hispanic & & & & & & $\begin{array}{l}-1.096 \\
(0.706)\end{array}$ \\
\hline Cut1 & $\begin{array}{c}-0.474 * * \\
(0.204)\end{array}$ & $\begin{array}{l}-0.377 \\
(0.259)\end{array}$ & $\begin{array}{l}-0.464 \\
(0.288)\end{array}$ & $\begin{array}{c}-0.697^{*} \\
(0.361)\end{array}$ & $\begin{array}{c}-0.712^{* *} \\
(0.300)\end{array}$ & $\begin{array}{c}-1.43^{* *} \\
(0.651)\end{array}$ \\
\hline Cut2 & $\begin{array}{l}-0.257 \\
(0.203)\end{array}$ & $\begin{array}{l}-0.159 \\
(0.259)\end{array}$ & $\begin{array}{l}-0.246 \\
(0.287)\end{array}$ & $\begin{array}{l}-0.474 \\
(0.360)\end{array}$ & $\begin{array}{l}-0.491 \\
(0.299)\end{array}$ & $\begin{array}{c}-1.208 * \\
(0.649)\end{array}$ \\
\hline Cut3 & $\begin{array}{c}0.104 \\
(0.203)\end{array}$ & $\begin{array}{c}0.202 \\
(0.259)\end{array}$ & $\begin{array}{c}0.114 \\
(0.288)\end{array}$ & $\begin{array}{l}-0.104 \\
(0.360)\end{array}$ & $\begin{array}{l}-0.121 \\
(0.296)\end{array}$ & $\begin{array}{c}-0.842 \\
(0.647)\end{array}$ \\
\hline Cut4 & $\begin{array}{l}1.21^{* * * *} \\
(0.222)\end{array}$ & $\begin{array}{l}1.31 * * * \\
(0.275)\end{array}$ & $\begin{array}{l}1.24 * * * \\
(0.302)\end{array}$ & $\begin{array}{l}1.04 * * * \\
(0.368)\end{array}$ & $\begin{array}{l}1.00 * * * \\
(0.307)\end{array}$ & $\begin{array}{c}0.275 \\
(0.647)\end{array}$ \\
\hline Cut5 & $\begin{array}{l}1.64 * * * \\
(0.248)\end{array}$ & $\begin{array}{l}1.75^{* * * *} \\
(0.299)\end{array}$ & $\begin{array}{l}1.69 * * * \\
(0.324)\end{array}$ & $\begin{array}{c}1.49 * * * \\
(0.387)\end{array}$ & $\begin{array}{l}1.43 * * * \\
(0.326)\end{array}$ & $\begin{array}{c}0.711 \\
(0.657)\end{array}$ \\
\hline Cut6 & $\begin{array}{l}1.72 * * * \\
(0.254)\end{array}$ & $\begin{array}{l}1.82 * * * \\
(0.305)\end{array}$ & $\begin{array}{l}1.76^{* * * *} \\
(0.329)\end{array}$ & $\begin{array}{l}1.57 * * * \\
(0.391)\end{array}$ & $\begin{array}{l}1.51 * * * \\
(0.330)\end{array}$ & $\begin{array}{c}0.783 \\
(0.660)\end{array}$ \\
\hline Pseudo $\mathrm{R}^{2}$ & 0 & 0.0014 & 0.0059 & 0.0171 & 0.0082 & 0.0067 \\
\hline Observations & 147 & 147 & 147 & 147 & 147 & 147 \\
\hline $\begin{array}{l}\text { Notes: Standard err } \\
\begin{aligned} \text { Excluded (reference } \\
-\quad \text { Mother (f } \\
-\quad \text { Girl (for b } \\
-\quad 4 \text { year old } \\
-\quad \text { White (for }\end{aligned}\end{array}$ & $\begin{array}{l}\text { n parenthe } \\
\text { mmy varia } \\
\text { ather) } \\
\text { r } 3 \text { YO an } \\
\text { ack and H }\end{array}$ & $\begin{array}{l}\text { s; } * * * p<0 \\
\text { les: } \\
5 \text { YO) } \\
\text { spanic) }\end{array}$ & $01, * * p<0$ & $5, * \mathrm{p}<0.1$ & & \\
\hline
\end{tabular}




\begin{tabular}{|c|c|c|c|c|c|c|c|c|c|c|}
\hline \multirow[b]{3}{*}{ Selfish parent } & \multicolumn{2}{|c|}{ Model 1} & \multicolumn{2}{|c|}{ Model 2} & \multicolumn{2}{|c|}{ Model 3} & \multicolumn{2}{|c|}{ Model 4} & \multicolumn{2}{|c|}{ Model 5} \\
\hline & Selfish child & Generous child & Selfish child & Generous child & Selfish child & Generous child & Selfish child & Generous child & Self.child & Generous child \\
\hline & $\begin{array}{l}-0.483 \\
(0.406)\end{array}$ & $\begin{array}{l}0.570 \\
(0.652)\end{array}$ & $\begin{array}{l}-0.482 \\
(0.407)\end{array}$ & $\begin{array}{l}0.577 \\
(0.664)\end{array}$ & $\begin{array}{l}-0.485 \\
(0.407)\end{array}$ & $\begin{array}{c}0.563 \\
(0.653)\end{array}$ & $\begin{array}{l}-0.484 \\
(0.407)\end{array}$ & $\begin{array}{c}0.567 \\
(0.665)\end{array}$ & $\begin{array}{l}-0.486 \\
(0.407)\end{array}$ & $\begin{array}{c}0.549 \\
(0.655)\end{array}$ \\
\hline Generous parent & $\begin{array}{l}-0.380 \\
(0.492)\end{array}$ & $\begin{array}{c}0.231 \\
(0.825)\end{array}$ & $\begin{array}{l}-0.362 \\
(0.495)\end{array}$ & $\begin{array}{c}0.421 \\
(0.845)\end{array}$ & $\begin{array}{l}-0.381 \\
(0.492)\end{array}$ & $\begin{array}{c}0.228 \\
(0.826)\end{array}$ & $\begin{array}{l}-0.364 \\
(0.495)\end{array}$ & $\begin{array}{c}0.429 \\
(0.846)\end{array}$ & $\begin{array}{l}-0.396 \\
(0.503)\end{array}$ & $\begin{array}{c}0.100 \\
(0.842)\end{array}$ \\
\hline Boy & & & $\begin{array}{c}0.134 \\
(0.367)\end{array}$ & $\begin{array}{l}1.433 * * \\
(0.650)\end{array}$ & & & $\begin{array}{c}0.135 \\
(0.367)\end{array}$ & $\begin{array}{l}1.438^{* *} \\
(0.651)\end{array}$ & & \\
\hline Father & & & & & $\begin{array}{c}0.075 \\
(0.386)\end{array}$ & $\begin{array}{c}0.227 \\
(0.601)\end{array}$ & $\begin{array}{c}0.077 \\
(0.387)\end{array}$ & $\begin{array}{c}0.250 \\
(0.615)\end{array}$ & & \\
\hline Black & & & & & & & & & $\begin{array}{l}0.058 \\
(0.564)\end{array}$ & $\begin{array}{c}0.645 \\
(0.932)\end{array}$ \\
\hline Hispanic & & & & & & & & & $\begin{array}{l}-0.105 \\
(0.515)\end{array}$ & $\begin{array}{l}0.050 \\
(0.905)\end{array}$ \\
\hline Constant & $\begin{array}{c}0.717 * * * \\
(0.266)\end{array}$ & $\begin{array}{c}-1.435^{* * *} \\
(0.498)\end{array}$ & $\begin{array}{c}0.654 * * \\
(0.315)\end{array}$ & $\begin{array}{c}-2.323 * * * \\
(0.689)\end{array}$ & $\begin{array}{c}0.693 * * \\
(0.292)\end{array}$ & $\begin{array}{c}-1.510 * * * \\
(0.539)\end{array}$ & $\begin{array}{l}0.630^{*} \\
(0.338)\end{array}$ & $\begin{array}{c}-2.410 * * * \\
(0.727)\end{array}$ & $\begin{array}{c}0.757 \\
(0.476)\end{array}$ & $\begin{array}{l}-1.662^{*} \\
(0.873)\end{array}$ \\
\hline Pseudo R2 & & & & & & & & & & \\
\hline Observations & 147 & 147 & 147 & 147 & 147 & 147 & 147 & 147 & 147 & 147 \\
\hline
\end{tabular}

Standard errors in parentheses. $* * * \mathrm{p}<0.01, * * \mathrm{p}<0.05, * \mathrm{p}<0.1$.

Omitted (reference) dummy variable for Selfish parent and Generous parent is Fair parent. 
Table 5. Emulation Effect for Children: Ordered Probit with Child Fixed Effects

\begin{tabular}{|c|c|c|c|c|c|c|c|c|c|}
\hline & (1) & (2) & (3) & (4) & (5) & (6) & (7) & (8) & (9) \\
\hline$X_{S} * \mathrm{R}$ & $\begin{array}{l}-0.040 \\
(0.047)\end{array}$ & $\begin{array}{l}-0.063 \\
(0.080)\end{array}$ & $\begin{array}{c}0.140 * * \\
(0.065)\end{array}$ & $\begin{array}{c}0.962 * * * \\
(0.124)\end{array}$ & $\begin{array}{c}1.001 * * * \\
(0.128)\end{array}$ & $\begin{array}{c}0.943 * * * \\
(0.141)\end{array}$ & $\begin{array}{c}0.954 * * * \\
(0.142)\end{array}$ & $\begin{array}{l}-0.074 \\
(0.085)\end{array}$ & $\begin{array}{l}-0.014 \\
(0.071)\end{array}$ \\
\hline Father* $X_{S} * \mathrm{R}$ & & $\begin{array}{c}0.033 \\
(0.111)\end{array}$ & & & & $\begin{array}{c}0.083 \\
(0.127)\end{array}$ & $\begin{array}{c}0.118 \\
(0.130)\end{array}$ & & \\
\hline Mother* $X_{S} * \mathrm{R}$ & & $\begin{array}{c}0.035 \\
(0.116)\end{array}$ & & & & $\begin{array}{c}0.000 \\
(0.131)\end{array}$ & $\begin{array}{c}0.070 \\
(0.140)\end{array}$ & & \\
\hline Boy* $X_{S} * \mathrm{R}$ & & & $\begin{array}{c}-0.404 * * * \\
(0.098)\end{array}$ & & $\begin{array}{l}-0.150 \\
(0.109)\end{array}$ & & $\begin{array}{l}-0.171 \\
(0.116)\end{array}$ & & \\
\hline$Y_{N I} * X_{S} * \mathrm{R}$ & & & & $\begin{array}{c}-0.387 * * * \\
(0.043)\end{array}$ & $\begin{array}{c}-0.375 * * * \\
(0.044)\end{array}$ & $\begin{array}{c}-0.391 * * * \\
(0.044)\end{array}$ & $\begin{array}{c}-0.378 * * * \\
(0.045)\end{array}$ & & \\
\hline $\begin{array}{l}\text { Selfish } \\
\text { Child }^{*} X_{S} * \mathrm{R}\end{array}$ & & & & & & & & $\begin{array}{c}0.424 * * * \\
(0.118)\end{array}$ & \\
\hline $\begin{array}{l}\text { Generous } \\
\text { Child }^{*} X_{S}{ }^{*} \mathrm{R}\end{array}$ & & & & & & & & $\begin{array}{c}-0.597 * * * \\
(0.134)\end{array}$ & \\
\hline $3 \mathrm{YO}^{*} X_{S}{ }^{*} \mathrm{R}$ & & & & & & & & & $\begin{array}{l}-0.013 \\
(0.112)\end{array}$ \\
\hline $\begin{array}{l}5 \mathrm{YO}^{*} X_{S} * \mathrm{R} \\
3 \mathrm{YO}^{*} X_{S} * \mathrm{R}\end{array}$ & & & & & & & & & $\begin{array}{l}-0.080 \\
(0.113)\end{array}$ \\
\hline Cut1 & $\begin{array}{c}-9.454 \\
(524.247)\end{array}$ & $\begin{array}{c}-9.443 \\
(524.320)\end{array}$ & $\begin{array}{c}-10.055 \\
(516.885)\end{array}$ & $\begin{array}{c}-13.862 \\
(957.429)\end{array}$ & $\begin{array}{c}-13.971 \\
(956.357)\end{array}$ & $\begin{array}{c}-13.801 \\
(960.212)\end{array}$ & $\begin{array}{c}-13.924 \\
(959.347)\end{array}$ & $\begin{array}{c}-11.840 \\
(1,066.580)\end{array}$ & $\begin{array}{c}-9.428 \\
(524.391)\end{array}$ \\
\hline Cut2 & $\begin{array}{c}-8.821 \\
(524.247)\end{array}$ & $\begin{array}{c}-8.810 \\
(524.320)\end{array}$ & $\begin{array}{c}-9.383 \\
(516.885)\end{array}$ & $\begin{array}{c}-12.953 \\
(957.429)\end{array}$ & $\begin{array}{c}-13.061 \\
(956.357)\end{array}$ & $\begin{array}{c}-12.888 \\
(960.212)\end{array}$ & $\begin{array}{c}-13.011 \\
(959.347)\end{array}$ & $\begin{array}{c}-11.125 \\
(1,066.580)\end{array}$ & $\begin{array}{c}-8.794 \\
(524.391)\end{array}$ \\
\hline Cut3 & $\begin{array}{c}-7.888 \\
(524.247)\end{array}$ & $\begin{array}{c}-7.877 \\
(524.320)\end{array}$ & $\begin{array}{c}-8.406 \\
(516.885)\end{array}$ & $\begin{array}{c}-11.648 \\
(957.429)\end{array}$ & $\begin{array}{c}-11.751 \\
(956.357)\end{array}$ & $\begin{array}{c}-11.583 \\
(960.212)\end{array}$ & $\begin{array}{c}-11.702 \\
(959.347)\end{array}$ & $\begin{array}{c}-10.006 \\
(1,066.580)\end{array}$ & $\begin{array}{c}-7.863 \\
(524.391)\end{array}$ \\
\hline Cut4 & $\begin{array}{c}-5.932 \\
(524.247)\end{array}$ & $\begin{array}{c}-5.922 \\
(524.320)\end{array}$ & $\begin{array}{c}-6.328 \\
(516.885)\end{array}$ & $\begin{array}{c}-8.926 \\
(957.429)\end{array}$ & $\begin{array}{c}-9.016 \\
(956.357)\end{array}$ & $\begin{array}{c}-8.855 \\
(960.212)\end{array}$ & $\begin{array}{c}-8.960 \\
(959.347)\end{array}$ & $\begin{array}{c}-7.505 \\
(1,066.580)\end{array}$ & $\begin{array}{c}-5.904 \\
(524.391)\end{array}$ \\
\hline Cut5 & $\begin{array}{c}-5.440 \\
(524.247)\end{array}$ & $\begin{array}{c}-5.428 \\
(524.320)\end{array}$ & $\begin{array}{c}-5.799 \\
(516.885)\end{array}$ & $\begin{array}{c}-8.247 \\
(957.429)\end{array}$ & $\begin{array}{c}-8.325 \\
(956.357)\end{array}$ & $\begin{array}{c}-8.171 \\
(960.212)\end{array}$ & $\begin{array}{c}-8.261 \\
(959.347)\end{array}$ & $\begin{array}{c}-6.889 \\
(1,066.580)\end{array}$ & $\begin{array}{c}-5.410 \\
(524.391)\end{array}$ \\
\hline Cut6 & $\begin{array}{c}-5.329 \\
(524.247)\end{array}$ & $\begin{array}{c}-5.317 \\
(524.320)\end{array}$ & $\begin{array}{c}-5.680 \\
(516.885)\end{array}$ & $\begin{array}{c}-8.106 \\
(957.429)\end{array}$ & $\begin{array}{c}-8.183 \\
(956.357)\end{array}$ & $\begin{array}{c}-8.028 \\
(960.212)\end{array}$ & $\begin{array}{c}-8.116 \\
(959.347)\end{array}$ & $\begin{array}{c}-6.768 \\
(1,066.580)\end{array}$ & $\begin{array}{c}-5.299 \\
(524.391)\end{array}$ \\
\hline Pseudo $\mathrm{R}^{2}$ & 0.398 & 0.398 & 0.422 & 0.54 & 0.54 & 0.54 & 0.54 & 0.477 & 0.399 \\
\hline Observations & 234 & 234 & 234 & 234 & 234 & 234 & 234 & 234 & 234 \\
\hline
\end{tabular}

Standard errors in parentheses. $* * * \mathrm{p}<0.01, * * \mathrm{p}<0.05, * \mathrm{p}<0.1$ 
Table 6. Teaching/Role Modeling Effect for Parents: Ordered Probit with Parent Fixed Effects

\begin{tabular}{|c|c|c|c|c|c|c|}
\hline & $(1)$ & $(2)$ & (3) & (4) & $(5)$ & (6) \\
\hline \multirow[t]{2}{*}{$D_{\text {show }}$} & -0.064 & $-0.370 *$ & -0.052 & 0.092 & -0.087 & -0.233 \\
\hline & $(0.174)$ & $(0.213)$ & $(0.248)$ & $(0.435)$ & $(0.286)$ & $(0.258)$ \\
\hline \multirow[t]{2}{*}{ Father* $D_{\text {show }}$} & & $0.996^{* *}$ & & & & \\
\hline & & $(0.389)$ & & & & \\
\hline \multirow[t]{2}{*}{ Boy* $D_{\text {show }}$} & & & -0.023 & & & \\
\hline & & & $(0.346)$ & & & \\
\hline \multirow[t]{2}{*}{ Black* $D_{\text {show }}$} & & & & -0.304 & & \\
\hline & & & & $(0.535)$ & & \\
\hline \multirow[t]{2}{*}{ Hispanic* $D_{\text {show }}$} & & & & -0.114 & & \\
\hline & & & & $(0.496)$ & & \\
\hline \multirow[t]{2}{*}{ Selfish child* $D_{\text {show }}$} & & & & & -0.386 & \\
\hline & & & & & $(0.380)$ & \\
\hline \multirow[t]{2}{*}{ Generous child* $D_{\text {show }}$} & & & & & $1.898 * * *$ & \\
\hline & & & & & $(0.624)$ & \\
\hline \multirow[t]{2}{*}{ Age $3 * D_{\text {show }}$} & & & & & & 0.610 \\
\hline & & & & & & $(0.416)$ \\
\hline \multirow[t]{2}{*}{ Age $5^{*} D_{\text {show }}$} & & & & & & -0.036 \\
\hline & & & & & & $(0.435)$ \\
\hline \multirow[t]{2}{*}{ Cut1 } & $-3.985 * * *$ & $-3.776 * * *$ & $-3.991 * * *$ & $-3.943 * * *$ & $-3.444 * * *$ & $-4.127 * * *$ \\
\hline & $(0.977)$ & $(1.030)$ & $(0.980)$ & $(0.981)$ & $(1.156)$ & $(0.983)$ \\
\hline \multirow[t]{2}{*}{ Cut2 } & $-2.925 * * *$ & $-2.686 * * *$ & $-2.931 * * *$ & $-2.888 * * *$ & $-2.312 * *$ & $-3.055 * * *$ \\
\hline & $(0.952)$ & $(1.007)$ & $(0.955)$ & $(0.956)$ & $(1.136)$ & $(0.956)$ \\
\hline \multirow[t]{2}{*}{ Cut3 } & -0.038 & 0.303 & -0.043 & -0.017 & 0.882 & -0.120 \\
\hline & $(0.878)$ & $(0.940)$ & $(0.881)$ & $(0.884)$ & (1.094) & $(0.873)$ \\
\hline \multirow[t]{2}{*}{ Cut4 } & $3.455 * * *$ & $3.878 * * *$ & $3.450 * * *$ & $3.485 * * *$ & $4.504 * * *$ & $3.411 * * *$ \\
\hline & $(0.931)$ & $(1.000)$ & $(0.934)$ & $(0.937)$ & $(1.149)$ & $(0.927)$ \\
\hline \multirow[t]{2}{*}{ Cut5 } & $4.711 * * *$ & $5.178 * * *$ & $4.706 * * *$ & $4.747 * * *$ & $5.789 * * *$ & $4.680 * * *$ \\
\hline & $(0.969)$ & $(1.041)$ & $(0.972)$ & $(0.976)$ & (1.182) & $(0.966)$ \\
\hline \multirow[t]{2}{*}{ Cut6 } & $5.388 * * *$ & $5.859 * * *$ & $5.382 * * *$ & $5.429 * * *$ & $6.491 * * *$ & $5.378 * * *$ \\
\hline & $(0.993)$ & $(1.063)$ & $(0.996)$ & $(1.002)$ & $(1.205)$ & $(0.992)$ \\
\hline \multicolumn{7}{|l|}{ Pseudo R2 } \\
\hline Observations & 292 & 292 & 292 & 292 & 292 & 292 \\
\hline
\end{tabular}




\section{Supplementary Material - Not for Publication}

\section{Appendices}

\section{Figure 1: Parent and Child Experimental Set-Up}

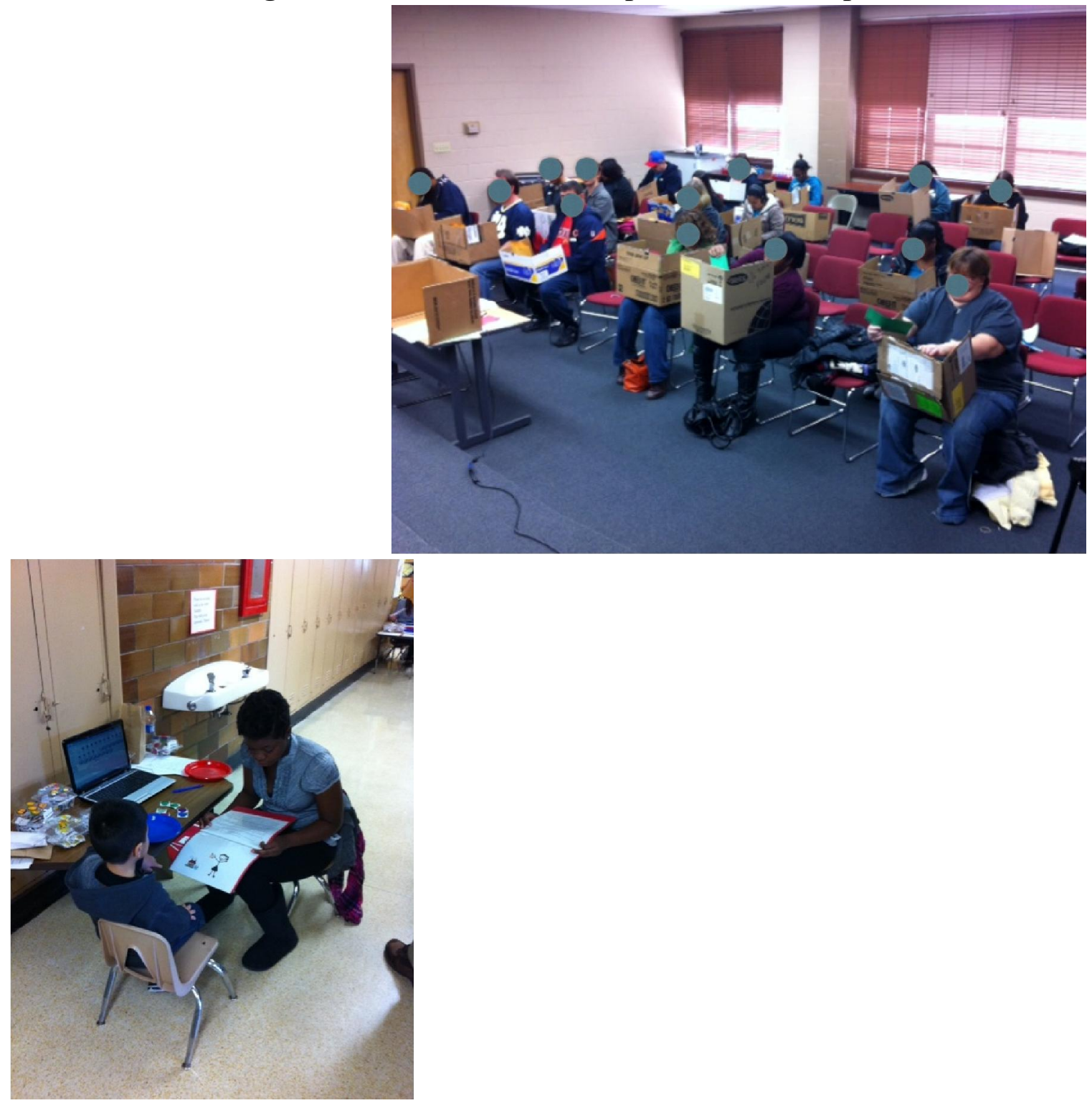

In the Parent Room, Left-Cardboard privacy screens are used to obscure decisions of participants. In the Child Room, Right - Children participate one-on-one with an experimenter. Participant faces are obscured to protect confidentiality.

\section{Appendix I: Parent Instructions and Sample Inserts \\ a) Order No Show/Show Instructions \\ PARENT ACTIVITY}

You have received your $\$ 15$ show up fee. Now we will start the activity

Instructions (a) 
Welcome to the parent activity. In this activity we want to see the choices that people make. You will be making the choices on your own and in private. So it is very important that you remain silent and do not look at other people's choices. If you have any questions, please raise your hand and I will come answer your questions in private.

What will we be doing? In the activity, you are going to divide $\$ 6$ between yourself and a person with whom you've been paired - your match. You will be asked to make this decision four times (with four different matches). Each time, you may keep all or some of the money for yourself or share all or some of it with your match.

Examples:

You may keep $\$ 6$ and give $\$ 0$.

You may keep $\$ 4$ and give $\$ 2$

You may keep $\$ 3$ and give $\$ 3$.

You may keep $\$ 2$ and give $\$ 4$.

You may keep $\$ 1$ and give $\$ 5$.

You may keep $\$ 0$ and give $\$ 6$.

You will never be matched with the same person more than one time, and no one else from the activity will be matched with the same person you are matched with.

You will get to take home the cash you choose to keep. You will get $\$ 6$ dollars for each of the four matches to divide between yourself and your match. You will put the dollars that you want to keep in your white envelope, and the dollars that you want to give to your match in the green envelope for your match. Your match will receive the green envelope, which will contain the dollars that you chose to send him/her.

How do you know who you are matched with? You will not know who you are matched with, since your match is anonymous. But you will know some information about the match. You will find out whether your match is male or female, and will get some information about the suburb in which your match lives. Also all of the matches are parents of preschool and elementary school children who did not (and will not) get a chance to do this activity.

The match will not know anything about you. The match will only get the letter that you will put in the green envelope about the activity and will get what you sent them.

There will be two rounds - in each round, you make the decision for two different matches. So - you will have four different matches during the activity today.

You have two big envelopes - after each round, that's where you'll put your dollars. The "SEND" envelope is for the matches. Please put your GECC ID sticker on your SEND envelope. The "KEEP" envelope is for you - please put your GECC ID sticker on your KEEP envelope.

\section{ROUND ONE}

In Round 1, you get to decide for two different matches.

Anything you do in the round will not be revealed to teachers and administrators. 
In this round, some children from today's activity may be shown the choices that you made before they make their choices in the child activity right after this. However, your own child will not see the choices you made for this round.

We will pass around one set of materials for each of your matches.

\section{In each set you have:}

- A white envelope that will be the envelope for you. The dollars you put in this envelope will be yours to keep.

- A green envelope for the match, with information about this match

- A letter to put into the green envelope for the match

- $\$ 6$ for this match decision

Please read the information about your match carefully - it will be the only thing you get to find out about your match!

You got $\$ 6$ to divide between you and one match, and $\$ 6$ to divide between you and the other match. Make sure you don't mix up the money - you have two separate sets.

Go ahead and put the amount you want to keep in your white envelope, and the amount you want to give to your match in the green envelope for each match separately. Please do this in private and don't talk to anyone about your choice. Remember, the only thing you know about your match is some information about him/her - that's taped to the front of the envelope.

Okay - is everyone finished? Great. Please place both of your white envelopes in the big folder with your name on it. Put the green envelopes in the SEND folder.

\section{ROUND TWO}

In Round 2, you again get to decide for two different matches, the same as you did in round 1. You will have two different sets of materials.

Anything you do in this round will not be revealed to teachers and administrators.

But there is one difference in round 2.

In this round we will show your child the choices you made before he/she makes some of his/her choices in the child activity that's just getting started.

We will pass around one set of materials for each of your matches.

\section{$\underline{\text { In each set you have: }}$}

- A white envelope that will be the envelope for you. The dollars you put in this envelope will be yours to keep.

- A green envelope for the match, with information about this match

- A letter to put into the green envelope for the match

- $\$ 6$ for this match decision 
Please read the information about your match carefully - it will be the only thing you get to find out about your match!

You got $\$ 6$ to divide between you and one match, and $\$ 6$ to divide between you and the other match. Make sure you don't mix up the money - you have two separate sets.

Go ahead and put the amount you want to keep in your white envelope, and the amount you want to give to your match in the green envelope for each match separately. Please do this in private and don't talk to anyone about your choice. Remember, the only thing you know about your match is some information about $\mathrm{him} / \mathrm{her}$ - that's taped to the front of the envelope.

Okay - is everyone finished? Great. Please place both of your white envelopes in the big folder with your GECC ID on it. Pass the SEND envelope to the front and we will collect it.

\section{b) Sample Information Sets, Rich and Poor, Female INFORMATION ABOUT THIS MATCH:}

Gender: Female

Lives in a neighborhood where yearly incomes vary around the mid-point of $\mathbf{\$ 8 8 , 1 9 3}$. This income means that there is about $\mathbf{\$ 4 8 , 1 0 5}$ for each person in a family.

Lives in a neighborhood where $96 \%$ of people own their home and the average cost of a home is $\$ 268,700$.

\section{INFORMATION ABOUT THIS MATCH:}

Gender: Female

Lives in a neighborhood where yearly incomes vary around the mid-point of $\mathbf{\$ 3 9 , 1 1 6}$. This income means that there is about $\mathbf{\$ 1 5 , 9 2 4}$ for each person in a family.

Lives in a neighborhood where $65 \%$ of people own their home and the average cost of a home is $\$ 133,300$.

\section{c) Letter for Match - Parents included this letter in the "send" envelope. The letter shows the participant that his/her information is not revealed.}

Dear Parent,

You are receiving an envelope sent by a parent at the Griffin Early Childhood Center (GECC) who participated in an activity. 
The parent got $\$ 6$ from the GECC, and chose how many dollars to keep, and how many dollars to send to you. The parent did not know who you are, just like you will not know who the parent is.

We do not know if your envelope contains any money, but we hope that you enjoy this gift if it does!

Sincerely,

- The Griffin Early Childhood Center

If you are interested in learning more about our programs, please visit X or call X.

\section{Appendix II: Child Instructions and Displays a) Child Instructions Examples - Rich, Poor, Adult Influence Rich Girl - (Rounds 1/2) \\ Let's pick the stickers you will play with in the first game. Which sticker pack do you want to play with} [SHOW ALL STICKER PACKS].

Here is a picture of a girl from another school. This girl has a lot of toys to play with at her home. Do you see her toys in the picture? Show me where they are. This girl didn't get to play the game today.

Here are some stickers. [PUT 6 STICKERS ON TABLE] They are yours now. You are going to decide how many to keep, and how many to send to this girl. You can keep as many of your stickers as you want, and you can send none, some, or all of your stickers to her. It is up to you how many you keep and how many you send.

Any stickers you keep, you will put them on your plate, here. Any stickers you want to send to this other girl, you will put them on her plate, here. You get to take home the stickers on your plate, and this girl will take home the stickers on her plate.

Can you show me which plate is your plate?

(That's right, this is your plate. You take home the stickers in this plate - we'll put them in your bag for you). 
Can you show me which plate is the other girl's plate?

(That's right, this the other girl's plate. The other girl takes home the stickers in this plate - we'll put them in her bag).

Okay, go ahead and decide where to put the stickers, on your plate or on the other girls' plate, who has a lot of toys. Remember, it is up to you what you decide!

Great job, now I am going to put the stickers from your plate in YOUR BAG and the stickers from the other girl's plate in HER BAG to send to her.

\section{Poor Girl (Rounds 1/2)}

Let's go on to the next one.

Let's pick the stickers you will play with in the first game. Which sticker pack do you want to play with [SHOW ALL STICKER PACKS].

Here is a picture of a girl from a different school than your school. This girl does not have a lot of toys to play with at her home. Do you see her toys in the picture? Show me where they are. This girl didn't get to play the game today.

Here are some stickers. [PUT 6 STICKERS ON TABLE] They are yours now. You are going to decide how many to keep, and how many to send to the other girl. You can keep as many of your stickers as you want, and you can send none, some, or all of your stickers to the other girl. It is up to you how many you keep and how many you send.

Any stickers you keep, you will put them on your plate, here. Any stickers you want to send to the other girl, you will put them on her plate, here. You get to take home the stickers on your plate, and the other girl will take home the stickers on her plate.

Can you show me which plate is your plate?

(That's right, this is your plate. You take home the stickers in this plate - we'll put them in your bag for you).

Can you show me which plate is the other girl's plate? 
(That's right, this is the other girl's plate. The other girl takes home the stickers in this plate - we'll put them in her bag.).

Okay, go ahead and decide where to put the stickers, on your plate or on the other girls' plate, who doesn't have many toys. Remember, it is up to you what you decide!

Great job, now I am going to put the stickers from your plate in YOUR BAG and the stickers from the other girl's plate in HER BAG to send to her.

Let's go on to the next one.

\section{An Adult Influence, Poor Girl (Rounds 3/4)}

Let's pick the stickers you will play with in the first game. Which sticker pack do you want to play with [SHOW ALL STICKER PACKS].

Here is a picture of a girl from a different school than your school. This girl does not have a lot of toys to play with at her home. Do you see her toys in the picture? Show me where they are. This girl didn't get to play the game today.

Here are some stickers. [PUT 6 STICKERS ON TABLE] They are yours now. You are going to decide how many to keep, and how many to send to the other girl. You can keep as many of your stickers as you want, and you can send none, some, or all of your stickers to the other girl. It is up to you how many you keep and how many you send.

Any stickers you keep, you will put them on your plate, here. Any stickers you want to send to the other girl, you will put them on her plate, here. You get to take home the stickers on your plate, and the other girl will take home the stickers on her plate.

Can you show me which plate is your plate?

(That's right, this is your plate. You take home the stickers in this plate - we'll put them in your bag for you).

Can you show me which plate is the other girl's plate? 
(That's right, this is the other girl's plate. The other girl takes home the stickers in this plate - we'll put them in her bag.).

But before you make your own choice, I want to tell you that other people played a similar game before you. They did not play the game with the girl you played with but with similar people. Here is what another adult did (show animation)

Okay, go ahead and decide where to put the stickers, on your plate or on the other girls' plate, who doesn't have many toys. Remember, it is up to you what you decide!

Great job, now I am going to put the stickers from your plate in YOUR BAG and the stickers from the other girl's plate in HER BAG to send to her.

\section{b) Child Instructions Screens - Poor, Rich girls}
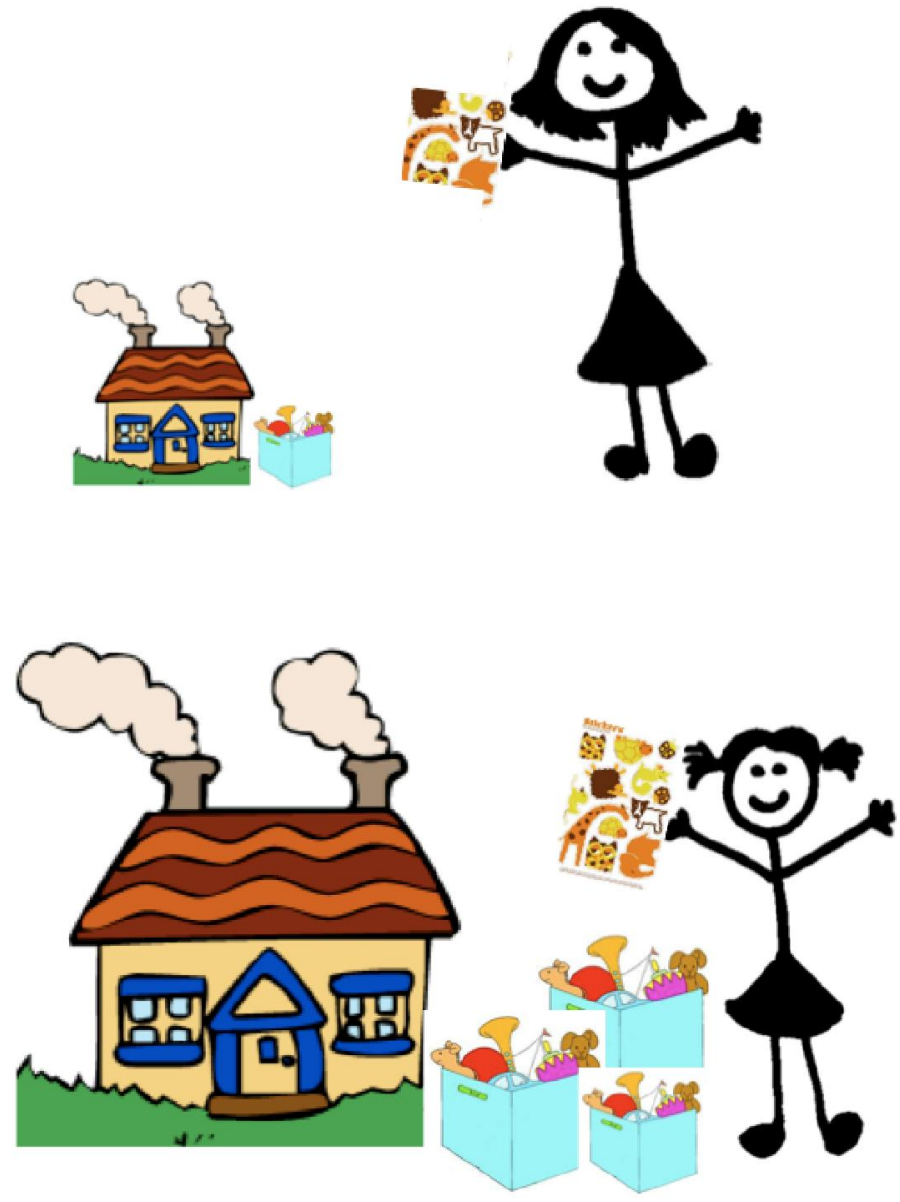

c) Influence Video - available upon request 